\title{
WHY HAS THE EMPLOYMENT-PRODUCTIVITY TRADEOFF AMONG INDUSTRIALIZED COUNTRIES BEEN SO STRONG?
}

\author{
Paul Beaudry \\ Fabrice Collard \\ Working Paper 8754 \\ http://www.nber.org/papers/w8754 \\ NATIONAL BUREAU OF ECONOMIC RESEARCH \\ 1050 Massachusetts Avenue \\ Cambridge, MA 02138 \\ February 2002
}

This paper was written while Beaudry was visiting GREMAQ, Toulouse. Ideas presented in this paper have been influenced by work between the first author and David Green. We want to thank Susanto Basu, Franck Portier, Javier Ortega, Gilles Saint-Paul and participants at the NBER EF meetings (Chicago), EUI seminar (Florence, Italy) and CREI seminar (Barcelona, Spain) for helpful comments. The views expressed herein are those of the authors and not necessarily those of the National Bureau of Economic Research.

(C) 2002 by Paul Beaudry and Fabrice Collard. All rights reserved. Short sections of text, not to exceed two paragraphs, may be quoted without explicit permission provided that full credit, including $\odot$ notice, is given to the source. 
Why has the Employment-Productivity Tradeoff among

Industrialized Countries been so strong?

Paul Beaudry and Fabrice Collard

NBER Working Paper No. 8754

February 2002

JEL No. O33, O41

\begin{abstract}
This paper is motivated by a set of cross-country observations on labor productivity growth among industrial countries over the period 1960-1997. In particular, we show that over this period, the speed of convergence among industrialized countries has decreased substantially while the negative effect of a country's own employment growth (or labor force growth) on labor productivity has increased dramatically. The main contribution of the paper is to show how these observations are consistent with the view that industrialized countries have been undergoing a particularly drastic technological revolution over the recent past. In effect, we show how the process of endogenous technological adoption, following the diffusion of a general purpose technology, can explain these observations by causing the emergence of an AK accumulation phase where demographic factors temporarily become an major determinant of labor productivity growth. Our estimation of the model implies that the AK phase has been in effect since the early to mid-seventies, but that this phase may now be coming to an end. An important contribution of the paper is to analyze growth experiences across advanced industrialized countries within an open economy framework and to evaluate the explanation by estimating a multicountry dynamic general model.
\end{abstract}

Paul Beaudry

Department of Economics

University of British Columbia

997-1873 East Mall

Vancouver, B.C.

Canada, V6T 1Z1

and NBER

paulbe@interchange.ubc.ca
Fabrice Collard

CNRS-GREMAQ and IDEI

Université de Toulouse I

Manufacture des tabacs, batiment $\mathrm{F}$

21 allée de Brienne

31000 Toulouse

France

fabrice.collard@univ-tlse1.fr 


\section{Introduction}

Neoclassical growth theory predicts that, along a transitional path, countries with higher rates of labor force growth should exhibit less labor productivity growth due to the need to use scarce capital to equip new workers. Moreover, the same theoretical framework suggests that, as countries become more integrated over time - i.e. in the presence of globalization - such a demographic related determinant of productivity growth should diminish, while the speed of convergence should increase due to the equalizing forces of international capital flows. However, as we will show, the data for major industrial countries since 1960 point towards the opposite pattern, that is, the tradeoff between labor productivity growth and labor force growth (or employment growth) appears to have increased over the recent past and the speed of convergence has decreased substantially. The object of the paper is to shed light on these observations. ${ }^{1}$

The primary motivation for our analysis is a series of cross-country regression regarding the determinants of labor productivity growth. As we will show, there has been a rather drastic change in the main observable determinants in labor productivity growth over the period 1960-97. In particular, over the first half of this period, the experience of industrial countries indicated only a small negative - generally insignificant — link between labor force growth (or employment growth) and the growth of output-per-worker. This observation is rather unsurprising and consistent with the view that rich industrialized countries may be well integrated and therefore country specific demographic factors, such as labor force growth, are not necessarily expected to be a very important determinant of labor productivity growth. However, over time, this relationship has radically changed. In effect, over the more recent period, we show that labor force growth has come to exhibit a very large and systematic negative link with labor productivity. We find such relationship to be surprisingly robust to instrument variable strategies, to the inclusion of additional regressors, and to the choice of countries. Moreover, we show that the speed of convergence among these countries decreased substantially over the period, with convergence virtually becoming an irrelevant force over the recent past.

This paper proposes a technology based explanation to the above observations. In particular, we argue that this pattern may likely be the cross-country expression of a process

\footnotetext{
${ }^{1}$ Many economists that have compared economic performance across major industrialized countries since the mid-seventies have noticed that most countries line up as either successes in employment growth or successes in labor productivity growth, but not both. At a qualitative level, such an observation is not puzzling since it is consistent with standard growth theory. However, we will show that a more quantitative look at the data reveals a quite intriguing and puzzling pattern.
} 
of endogenous technological adoption following the arrival of new means of production. In a sense, our explanation can be seen as providing evidence to the view that industrialized countries have been recently undergoing a major technological revolution of the kind emphasized, among others, by Caselli (1999), Basu and Weil (1998) and Zeira (1998). To make our point, we extend a standard neo-classical growth model along two dimensions. First, we allow for radical technological change in the form of the arrival and dissemination of an alternative means of production. ${ }^{2}$ This type of technological change is meant to capture ideas emphasized in the General Purpose Technology (GPT) literature. ${ }^{3}$ Secondly, we allow countries to be linked through international capital market as to make the model relevant for the set of advanced industrialized countries under study. ${ }^{4}$

Using this model, we show why countries with different rates of labor force growth would adjust differently to a major technological change. ${ }^{5}$ In particular, the model illustrates how the arrival of an alternative production process temporarily creates an AK type accumulation phase which triggers a large negative tradeoff between employment growth and labor productivity growth. The AK phase arises endogenously in our model as the result of decentralized decisions regarding the appropriate speed by which to adopt the new technology. In particular, because of the AK structure, slower capital deepening is experienced by high population growth countries since there is no counterbalancing force to trigger an inflow of capital. The central aspect of the paper is to show that the model can quantitatively replicate the observed changes in the cross-country regressions.

Our main conclusion from fitting the model to the data are that (i) over the period 19601997 advanced industrialized countries appear to have transited from a technology where accumulable factors accounted for approximately a 50\% share of income to a new means of production where they represent more than $60 \%$ of income, (ii) industrialized countries have adjusted at different speeds to this technological change due in large part to differences in their rates of labor force growth. In particular, we find that countries with high rates of labor force growth have not been able to take advantage as quickly of the new opportunities associated with capital deepening, but that this disadvantage may now have come to an end.

\footnotetext{
${ }^{2}$ In this paper we are pursuing a technology based explanation to the set of observations. A potentially relevant alternative explanation is the increase globalization of the economy. In future work we plan to explore this possibility and compare its merits with the technology based explanation developed here.

${ }^{3}$ See for example Bresnahan and Trajtenberg (1995).

${ }^{4}$ We do not assume that international capital mobility is perfect. Instead, we introduce a friction in the form of an intermediation cost which increases with the size of capital flows.

${ }^{5} \mathrm{~A}$ similar idea is pursued in Beaudry and Green (2001), but there the focus is on the effects of technological change on changes in the returns to education across countries.
} 
The remaining sections of the paper are structured as follows. In Section 2, we discuss a series of cross-country regressions linking output-per-worker to labor force growth and initial levels of output-per-worker. In Section 3, we present our baseline growth model where we allow technological change to arrive in both the form of labor augmenting progress and in the form of an increased access to a alternative means of producing goods. Throughout section 3 , we allow for only one accumulable factor which we refer to as capital. However, this capital stock should be thought as an aggregate of human and physical capital. We then derive the main theoretical implications of the model and provide a quantitative evaluation. In section 4, we extend the model to explicitly distinguish between human and physical capital, and we show how such an extended model helps explain the data. Finally, a last section offers concluding comments.

\section{Labor Productivity Growth and Demographics: Some In- triguing Observations}

In this section, we report a set of cross-country regressions relating growth in output-perworker to labor force growth and the initial level of output-per-worker. We focus exclusively on the experiences of the 18 richest industrialized countries (as defined by their level of GDPper-capita in 1960) since it is a set of countries for which assuming common access to frontier technological opportunities appears most plausible. The 18 countries forming our sample are Australia, Austria, Belgium, Canada, Denmark, Finland, France, Germany, Iceland, Italy, Luxembourg, Netherlands, New Zealand, Norway, Sweden, Switzerland, United Kingdom and the United States. ${ }^{6}$ The data are taken from the OECD statistical compendium 1999, unless indicated otherwise. ${ }^{7}$

The main observation that we want to highlight is the extent to which the role of initial conditions and labor force growth in explaining labor productivity growth has changed over the 1960-1997 period. To see this more clearly, we begin by reporting estimates associated with a series of very simple rolling regressions. Our basic regression consists of regressing the growth in output-per-worker ${ }^{8}$ on the growth in labor force and the initial level of output-

\footnotetext{
${ }^{6}$ Our sample consists of the set of industrial countries where the level of per-capita-income in 1960 was greater that $48 \%$ of the US level. We found it natural to cut the sample at this point since it is where there was a rather large break in the data. For example, the next richest industrialized countries had per-capita-incomes below one third of the US level in 1960.

${ }^{7}$ The data on GDP in US\$, which is needed to calculate comparable initial levels of output-per-worker, are taken from the Heston and Summers data set.

${ }^{8}$ Output-per-worker is measured as GDP divided by total employment. However, our findings are robust to the use of private output per private employee as a measure of output-per-worker.
} 
per-worker, with each variable measured in relation to the given window. We chose a size of window of 19 years since it corresponds to half of our sample length. Nevertheless, in order to check the robustness of our results, we also explored window sizes between 15 to 25 years, all of which led to similar conclusions.

We estimated the relationship using ordinary least squares (OLS) and weighted least squares (WLS). In the latter case, the weights used in estimation correspond to the square root of the active population. ${ }^{9}$ Note that the main difference between our results by OLS and WLS are due to reducing the weight of Luxembourg and Iceland. Figures 1 and 2 plot the estimates of this relationship across the different windows. Figure 1 reports the estimated speed of convergence across the different windows, that is, it reports the estimated effect of the initial level of output-per-worker on the growth in output-per-worker for each window. The two different lines on the graph correspond to the estimates using OLS and WLS. Note that the years on the $\mathrm{X}$-axis in these figures correspond to the initial year of the window, that is, it begins in 1960 - for the 1960-1978 window - and ends in 1979 with the 1979-1997 window. Finally, all growth rates are calculated in yearly rates. ${ }^{10}$

Figure 1: Estimated Speed of Convergence

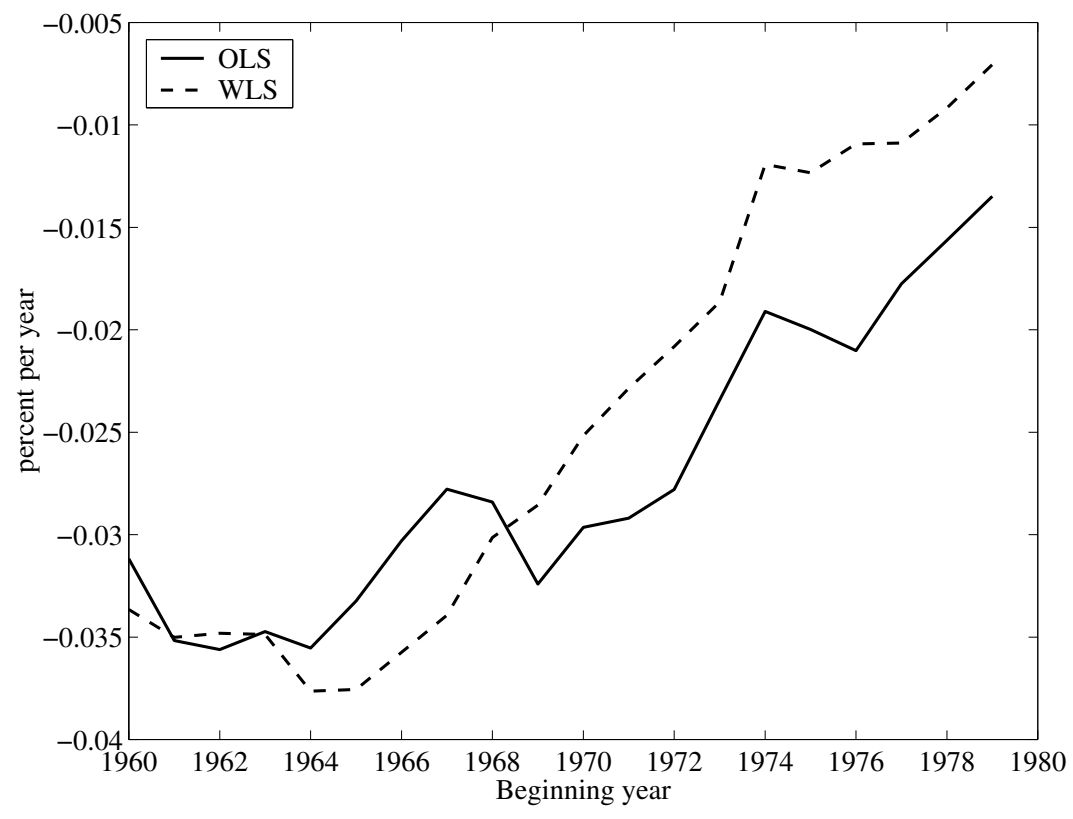

Figure 1 indicates that initially (over the windows starting in the early 60 s), industrial countries exhibited rapid convergence, with a significant speed of convergence of around $3.5 \%$

\footnotetext{
${ }^{9}$ Our measure of active population corresponds to all individuals aged between 15 and 64 .

${ }^{10}$ For windows starting after 1971, the rates of growth for West Germany were calculated using the yearly average up to 1991, in order to avoid any effect related to the German reunification.
} 
Figure 2: Estimated Effect of 1\% Labor Force Growth on Yearly Labor Productivity Growth

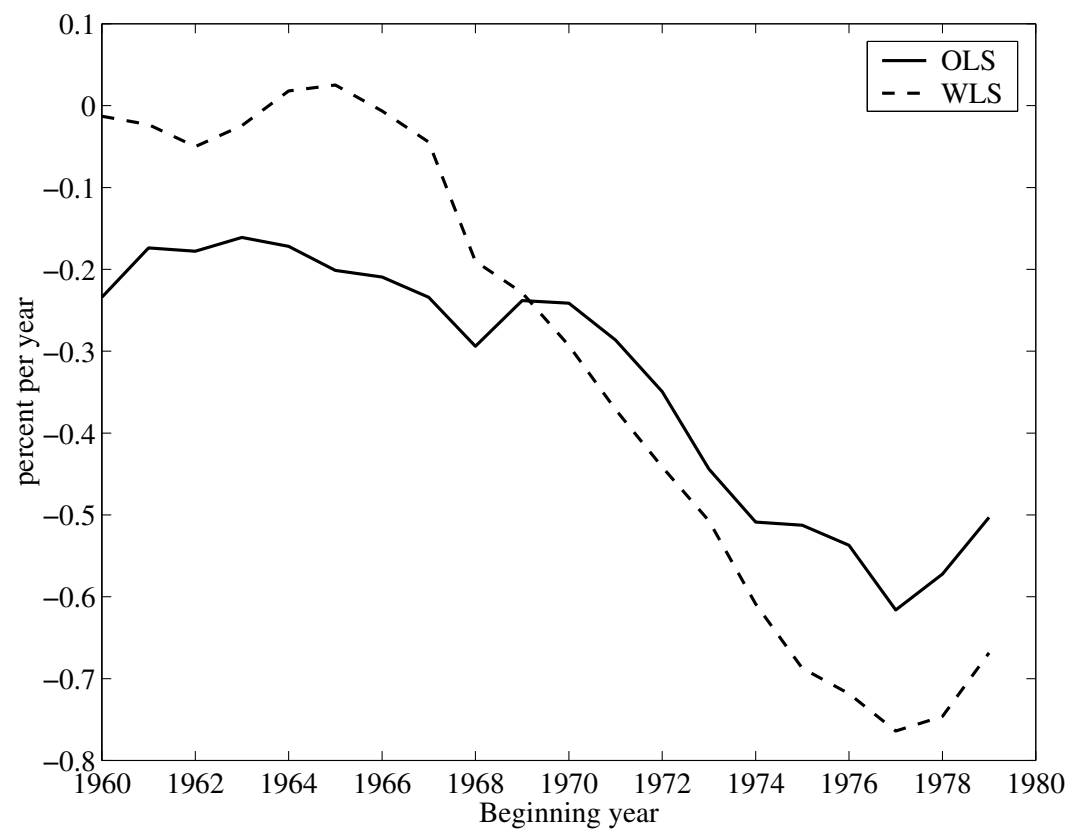

per year. However, over the sample period, this speed of convergence decreased substantially. In effect, in the latter period — for example the 1979-97 window — our estimates of the speed of convergence is divided by almost 3 relative to the 1960-1978 period, with the effect becoming statistically insignificant towards the end of the period. Although, by itself, this observation may not be very surprising, when juxtaposed with the changing effect of labor force growth, it becomes quite intriguing. Figure 2 plots the estimated effect of labor force growth on the growth of output-per-worker. In contrast to figure 1, we see the importance of this effect increase over time. In particular, our estimates of the effect starts near zero (for the 1960-1978 window) and gradually increases in importance as it reaches an estimate greater than -0.5 over time. Note that an estimate of -0.5 implies that a country with a growth in labor force of $1 \%$ experienced on average a growth in output-per-worker of $0.5 \%$ per-year less than a country with a zero growth in labor force (holding constant the initial level of labor productivity). To get a more precise idea of the magnitude and significance of the effects at the beginning and the end of the sample, table 1 reports the OLS and WLS estimates of these effects for the first and last window. In both cases, note that the estimates of the first and last window are found to be statistically different from each other at the $1 \%$ confidence level.

In order to further emphasize the magnitude of the change, in figure 3 we plot the ratio of these two coefficients for both estimated cases (OLS and WLS), that is, the ratio of the 
Table 1: Cross-Country Regressions for Growth of Output-per-capita

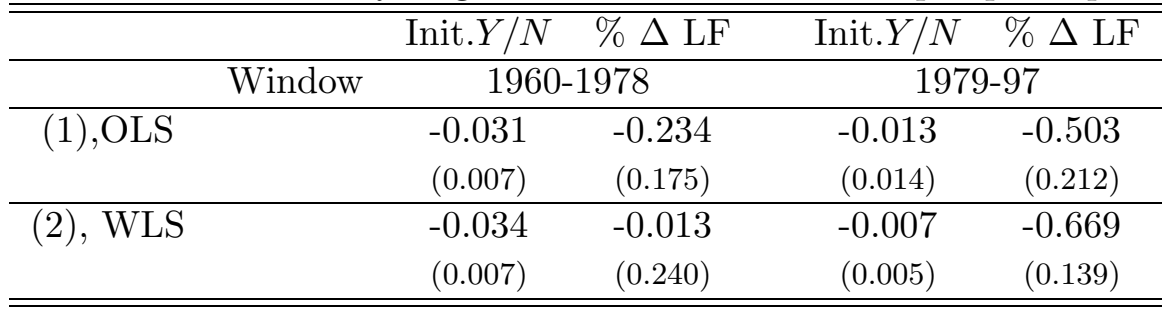

Note: Standard errors between parenthesis. Weights used in WLS is the square root of the countries' active population.

effect of labor force growth relative to the speed of convergence. Within a standard Solow growth model, this ratio can be interpreted as an estimate of the long-run effect on the level of labor productivity of a $1 \%$ difference in the growth of labor force. As can be seen from the figure, this ratio was quite close to zero - less than $8 \%$ in the early period, but increased to more than $40 \%$ (!!) in the later part of the sample. Although we are not claiming that this ratio appropriately reflects the long-run effect of labor force growth, we nevertheless believe that the change in this ratio summarizes our claim that the link between labor force growth and labor productivity growth has became surprisingly strong over the recent past. Before exploring the reason for the pattern presented in figures 1-3, we first

Figure 3: Implied Long-Run Effect of -1\% Labor Force Growth

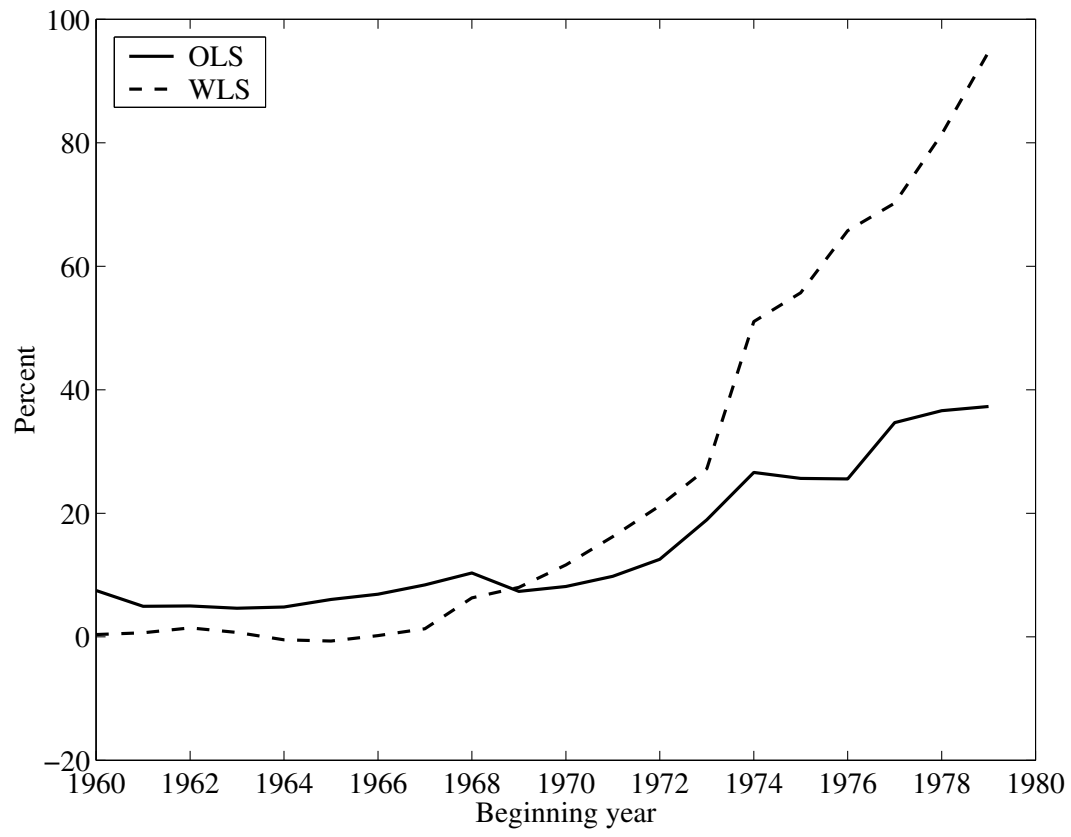

need to further establish its robustness. In particular, we want to claim that the pattern 
presented in these figures likely reflects a change in the causal structure running from labor force growth and initial conditions to labor productivity growth. Hence, to make such a claim plausible, we need to discuss potential issues related to the endogeneity of regressors and the omission of variables. ${ }^{11}$ To this end, we explored several changes in specification, sample and alternative instrumental variable strategies. Tables 1 through 3 report a small subset of cases we considered. ${ }^{12}$ For these cases, we report the estimate for the first window covering the period 1960-78, and the estimates associated with the last window 1979-1997. Furthermore, we report the OLS and WLS estimates for our sample of 18 countries. As will be shown, we found the pattern of increased importance of labor force growth (or employment growth) and decreased importance of convergence be to very robust.

The first issue we want to address is whether the pattern we are documenting could simply be capturing the indirect effects of certain labor market policies which may have favored labor productivity at the cost of increasing unemployment. ${ }^{13}$ If this were the whole story, it would have nothing to do with the type of interaction between technological adoption and demographically driven employment growth which we believe has been important. ${ }^{14}$ To see whether this could be the case, we include as an additional regressor the change in the countries unemployment rate over the corresponding period. The corresponding estimates are reported in panel 1 of table 2. As can be seen, the inclusion of the change in unemployment does not change the pattern we are emphasizing. We still observe the decrease in the speed of convergence and a similar increase in the importance of labor force growth in affecting labor productivity. In fact, our point estimates for both these variables are almost unaffected by the inclusion of the change in the rate of unemployment, both in terms of significance

\footnotetext{
${ }^{11}$ To understand the issues involved, it is helpful to keep in mind the following regression equation for labor productivity growth

$$
\Delta_{n}\left(\frac{Y_{i, t}}{L_{i, t}}\right)=\alpha_{0, t}+\alpha_{1, t} \log \left(\frac{Y_{i, t}}{L_{i, t}}\right)+\alpha_{2, t} \Delta_{n} L F_{i, t}+\alpha_{3, t} X_{i, t+n}+\epsilon_{i, t+n}
$$

Where $\Delta_{n} z_{t}=\left(\log \left(z_{t+n}\right)-\log \left(z_{t}\right)\right) / n, Y_{i, t} / L_{i, t}$ is labor productivity in country i at time $\mathrm{t}, n$ is the size of the window, $L F$ is the size of the labor force, and $X$ is a vector or other factors affecting labor productivity growth.

In our basic specification we did not include any $X_{i, t}$ variables. The omission of relevant $X$ is not a problem as long as they are not correlated with our two regressors of interest. However, since this may not be the case, in what follows we examine how the introduction of $X \mathrm{~s}$ affect our observations.

${ }^{12}$ Besides the cases we report, we also verified the robustness of our results with respect to controlling for changes in education attainment, the importance of immigration and the age composition of the labor force.

${ }^{13}$ See Blanchard (1997) for a discussion along these lines.

${ }^{14}$ Many economists argue that high labor productivity growth in Europe may have been caused mainly by institutions that have restricted employment. Our view is that this interpretation of the European experience is much too restrictive in that it does not recognize that demographic factors may have been an even more important factor for high labor productivity growth than what can be accounted for by the increase in unemployment.
} 
and magnitude for the whole sample. Moreover, our estimates of the effect of a change in unemployment on labor productivity are not found to be statistically significant in either the earlier or later sample. Hence, the pattern we are emphasizing does not appear to be driven simply by the behavior of unemployment: something more akin to an increased tradeoff between employment growth and productivity growth appears to be at work.

To further clarify this last point, in panel B of table 2 we use the growth in employment instead of the growth in the labor force as a regressor in addition to the initial level of output-per-worker. In panel $\mathrm{C}$ of table 2 , we further include the change in the rate of unemployment. The estimates in panel B are very similar to those of table 1, suggesting that it is demographic factors, through their effect on employment, which have increased in importance. Furthermore, in panel $\mathrm{C}$ we see that the change in the rate of unemployment is not a significant predictor of labor productivity growth once the effect of employment growth is taken into account. In other words, the data suggest that there has been an increase in the tradeoff between employment growth and productivity growth over this period regardless of the reason for the increased employment. Hence, the results from table 2 suggest that it is demographic factors that have played the dominant role in the process we are describing, not changes in unemployment - although we recognize that the later may have been a contributing factor.

The second issue we want to address is the robustness of our results to the inclusion of investment rates (in log form) as an additional regressor. ${ }^{15}$ Our investment rate variable was constructed as the average of the ratio of real investment in structures and equipment as a fraction of real GDP. In table 3, we report our estimates of convergence speed and the effects of labor force growth when the window-specific average rate of investment is included as an additional regressor. As can be seen from table 3, the inclusion of the rate of investment again leaves virtually unaltered our basic observations.

The third issue we choose to highlight is the extent to which the patterns in figures 1 and 2 may be driven by a particular set of countries, in this case, the predominantly anglo-saxon countries - i.e. the US, the UK, Canada, Australia, and New Zealand. To explore this issue, we ran our rolling regressions including a dummy variable for the five predominantly anglo-saxon countries (where the effect of the dummy variable is allowed to vary over time). The results of this estimation are reported in panel $\mathrm{A}$ of table 4 . In panel $\mathrm{B}$, we report the first and last window of the WLS estimate for the case where we exclude all 5 Anglo-

\footnotetext{
${ }^{15}$ Although not reported, we also verified the robustness of our results with respect to the inclusion of changes in education attainment.
} 
Table 2: Cross-Country Regressions: Controlling for the Change in the Unemployment Rate

\begin{tabular}{|c|c|c|c|c|c|c|c|}
\hline & \multicolumn{7}{|c|}{ Panel A } \\
\hline & & Init. $\frac{Y}{N}$ & $\% \Delta \mathrm{LF}$ & $\Delta \mathrm{Ur}$ & Init. $\frac{Y}{N}$ & $\% \Delta \mathrm{LF}$ & $\Delta \mathrm{Ur}$ \\
\hline \multirow{3}{*}{ (1), OLS } & \multirow[t]{5}{*}{ Window } & & $1960-78$ & & & 1979-97 & \\
\hline & & -0.031 & -0.166 & 223 & -.011 & -0.480 & .706 \\
\hline & & (0.007) & $(0.181)$ & (1.073) & $(0.015)$ & $(0.232)$ & (1.297) \\
\hline \multirow[t]{5}{*}{ (2), WLS } & & -0.039 & 0.085 & -2.071 & -0.005 & -0.614 & 0.442 \\
\hline & & $(0.006)$ & $(0.244)$ & $(1.509)$ & $(0.006)$ & $(0.153)$ & $(.502)$ \\
\hline & \multicolumn{7}{|c|}{ Panel B } \\
\hline & & Init. $\frac{Y}{N}$ & $\% \Delta$ Empl. & $\Delta \mathrm{Ur}$ & Init. $\frac{Y}{N}$ & $\% \Delta$ Empl. & $\Delta \mathrm{Ur}$ \\
\hline & Window & & 1960-78 & & & $1979-97$ & \\
\hline \multirow[t]{2}{*}{ (3), OLS } & & -0.031 & -0.237 & - & -0.011 & -0.477 & - \\
\hline & & $(0.007)$ & $(0.175)$ & & $(0.014)$ & $(0.194)$ & \\
\hline \multirow[t]{3}{*}{ (4), WLS } & & -0.035 & 0.042 & - & -0.005 & -0.627 & - \\
\hline & & $(0.008)$ & $(0.250)$ & & $(0.006)$ & $(0.115)$ & \\
\hline & \multicolumn{7}{|c|}{ Panel C } \\
\hline \multirow[t]{2}{*}{$(5)$, OLS } & & -0.035 & -0.166 & .230 & -0.011 & -0.461 & -0.197 \\
\hline & & $(0.007)$ & $(0.183)$ & $(1.229)$ & $(0.015)$ & $(0.230)$ & $(1.402)$ \\
\hline \multirow[t]{2}{*}{ (6), WLS } & & -0.039 & 0.020 & -.998 & -0.005 & -0.612 & -0.229 \\
\hline & & (0.011) & $(0.258)$ & $(1.711)$ & $(0.006)$ & $(0.152)$ & $(.588)$ \\
\hline
\end{tabular}

Note: Standard errors between parenthesis. Weights used in WLS is the square root of the countries' active population.

Table 3: Cross-Country Regressions: Controlling for Investment Rate

\begin{tabular}{|c|c|c|c|c|c|c|c|}
\hline & & Init. $\frac{Y}{N}$ & $\% \Delta \mathrm{LF}$ & $\frac{I}{Y}$ & Init. $\frac{Y}{N}$ & $\% \Delta \mathrm{LF}$ & $\frac{I}{Y}$ \\
\hline \multirow{3}{*}{ (1), OLS } & \multirow[t]{3}{*}{ Window } & \multicolumn{3}{|c|}{$1960-78$} & \multicolumn{3}{|c|}{$1979-97$} \\
\hline & & -0.032 & -0.231 & 0.001 & -0.007 & -0.638 & 0.020 \\
\hline & & $(0.008)$ & $(0.182)$ & $(0.008)$ & $(0.007)$ & $(0.222)$ & $(0.013)$ \\
\hline \multirow[t]{2}{*}{$(2)$, WLS } & & -0.028 & 0.009 & 0.018 & -0.003 & -0.746 & 0.009 \\
\hline & & $(0.007)$ & $(0.223)$ & $(1.865)$ & $(0.006)$ & $(0.151)$ & $(0.008)$ \\
\hline
\end{tabular}

Note: Standard errors between parenthesis. 
Table 4: Cross-Country Regressions: Controlling for Anglo-saxon Countries

\begin{tabular}{|c|c|c|c|c|c|c|c|}
\hline & \multicolumn{7}{|c|}{ Panel A } \\
\hline & & Init. $\frac{Y}{N}$ & $\% \Delta \mathrm{LF}$ & Dummy & Init. $\frac{Y}{N}$ & $\% \Delta \mathrm{LF}$ & Dummy \\
\hline \multirow{3}{*}{ (1), OLS } & Window & \multicolumn{3}{|c|}{$191960-78$} & \multicolumn{3}{|c|}{$101979-97$} \\
\hline & & -0.029 & -0.195 & -0.006 & -0.013 & -0.482 & -0.002 \\
\hline & & $(0.008)$ & $(0.185)$ & $(0.004)$ & $(0.015)$ & $(0.224)$ & $(0.004)$ \\
\hline \multirow[t]{3}{*}{ (2), WLS } & & -0.024 & 0.057 & -0.006 & -0.007 & -0.668 & -0.002 \\
\hline & & $(0.006)$ & $(0.181)$ & $(.004)$ & $(0.006)$ & $(0.152)$ & $(0.004)$ \\
\hline & \multicolumn{7}{|c|}{ Panel B } \\
\hline \multirow{3}{*}{ (1), WLS } & Window & \multicolumn{3}{|c|}{$1960-78$} & \multicolumn{3}{|c|}{ 1979-97 } \\
\hline & 13-countries & -0.041 & -0.088 & - & -0.024 & -0.771 & - \\
\hline & & $(0.012)$ & $(0.370)$ & & $(0.014)$ & $(0.224)$ & \\
\hline \multirow[t]{2}{*}{ (2), WLS } & 14-countries & -0.058 & 0.242 & - & -0.006 & -0.832 & - \\
\hline & & $(0.013)$ & $(0.441)$ & & $(0.008)$ & $(0.156)$ & \\
\hline
\end{tabular}

Note: standard errors between parenthesis. The 13 country sample excludes: US,Canada, Australia, New Zealand and the UK. The 14 country sample excludes: US, Canada, Australia and New Zealand. Weights used in WLS is the square root of the countries' active population.

saxon countries from our sample, which leaves us with a sample of 13 countries, and the case where we exclude only the non-european economies of Canada, Australia, New Zealand and the US, leaving us with 14 countries. As can be seen in the table, the effects we have been emphasizing are not driven solely by the anglo-saxon countries, since they appear in both restricted sub-samples. In fact, for our non-anglo-saxon sub-sample, the increased importance of labor force growth is estimated to be at least as important with the coefficient on labor force growth reaching close to -0.8 in the 1979-1997 window.

As a last robustness check, we explore two instrumental variable strategies aimed at addressing the possible endogeneity labor force growth. In the first case, we instrument labor force growth by the growth in the active population over each given window, which is a time varying instrument. In the second case, we instrument the labor force growth in each window by the growth in active population observed in the period 1960-1978, which is a non-timevarying instrument. The first procedure has the potential of mitigating potential biases that could be due to the endogeneity of participation decision. The second procedure, by using a time-invariant instrument, has the potential of minimizing simultaneity biases due to the endogeneity of the population growth itself - for example, biases that could be induced by the endogeneity of immigration. As can be seen in table 5, the resulting estimates for the window 1979-1997 using these two instrumental variable strategy suggests an even stronger increase in the effect of labor force growth than that found in table 1 (although less precise). 
Table 5: Cross-Country Regressions: Instrumental Variable Estimation

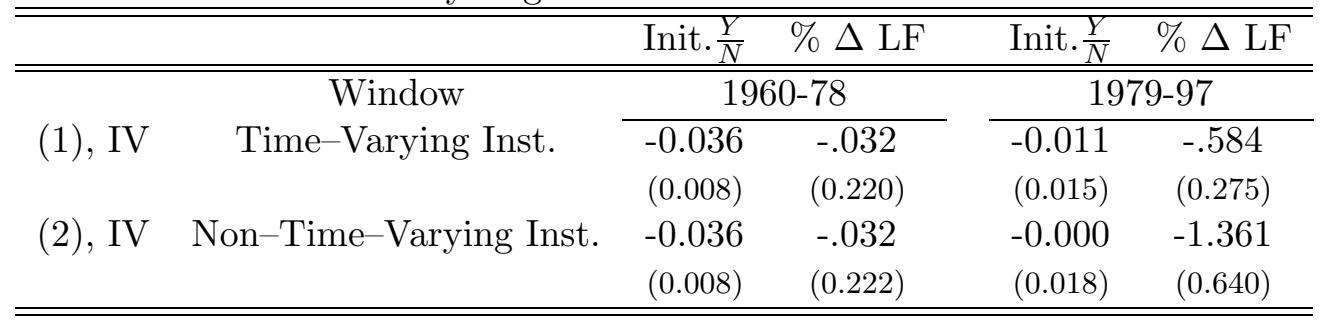

Note: Standard errors between parenthesis. In the time-varying case, we instrument labor force by the countries' growth in active population over the given window. In the non-time-varying case, we instrument labor force growth by the countries' growth in active population over the period 1960-78 for all windows.

Hence, it is unlikely that the pattern we are highlighting is being driven by the endogeneity of labor force growth.

Together, the results reported in tables 2 through 5 suggest that there has been a major change in the determinants of labor productivity growth across industrial countries, whereby the speed of converge has decreased and the effect of labor force growth has increased substantially.

\section{An International Growth Model with Endogenous Techno- logical Choice}

The pattern presented in figures 1 and 2 indicates a change in the determinants of labor productivity growth over the period 1960-1997, with a decrease in the speed of convergence and an increase in the importance of demographically driven employment growth. In this section, we propose a technology based explanation to these observations. In particular, our goal is to show that such a pattern may reflect the process by which industrialized countries have adjusted to a major technological change.

The type of major technological change we envision is one corresponding to the arrival and dissemination of a new production process, where the extent and speed of adoption are endogenously determined by country-specific market forces. In this sense, the model we develop shares features with the literature on General Purpose Technologies (GPT), and is a particular case of the class of endogenous technological choice model which have featured prominently in recent explanations of inequality trends. ${ }^{16}$ One important feature of our

\footnotetext{
${ }^{16}$ See for example, Acemoglu (1999), Basu and Weil (1998), Beaudry and Green (1998,2000), Caselli
} 
modelling approach is to propose an explanation to cross-country growth observation which does not treat individual countries as autonomous entities but instead considers them as a set of interlinked economies. ${ }^{17}$ This appears most relevant for the set of countries we are considering.

Our approach in this section is as follows. We first set out a baseline model where there are only two factors of production: a broad measure of capital and unskilled labor. We then use this model to show how the arrival of an alternative production process can generate the type of patterns depicted in figures 1 and 2 . We begin by a theoretical analysis which highlights the qualitative properties of the model. We then complement this analysis by a quantitative evaluation, which consists of an estimation and simulation strategy aimed at examining whether the model can quantitatively reproduce the patterns of figures 1 and 2 . Since our quantitative exercise consists of evaluating a dynamic general equilibrium model of 18 interlinked economies, the model is kept as simple as possible to render the task feasible. As we shall show, the main technological feature that allows to explain the pattern depicted in figures 1 and 2 consists of the arrival and dissemination of a new production process with the property that it uses accumulable factors more intensively; whether this greater intensity involves greater intensive use of human capital, physical capital or both.

\subsection{Theoretical Analysis}

\subsubsection{Technology}

We consider a set of economies, indexed by $i=1, \ldots, N$, which all produce the same homogenous good, that can be either consumed or invested. All firms have access to the same technological possibilities. Initially, firms in all the countries produce output using a traditional and well-established production process which depends on capital $K_{i, t}$ and efficient units of unskilled labor $\theta_{t} L_{i, t}$ according to the following constant returns to scale production function.

$$
Y_{i, t}=K_{i, t}^{\alpha}\left(\theta_{t} L_{i, t}\right)^{1-\alpha} \text { with } \alpha \in(0,1)
$$

(1999)and Zeira (1998). The model of endogenous technological choice most closely related to the current paper is probably that of Zeira (1998). Note that from a theoretical perspective, most models of endogenous technological choice are simple reinterpretations of models of international trade.

${ }^{17}$ Ventura (1998) also proposes an explanation of international growth patterns within a framework of interlinked economies. In ongoing work, we are examining the extent to which a model along the lines of Ventura's can explain the observations presented in figures 1 and 2. 
Throughout this section, we will refer to capital generically and interpret it as representing an aggregate of human and physical capital. ${ }^{18}$

In the above production function, we allow for factor augmenting technological change through growth in $\theta_{t}$, which is assumed to evolve as

$$
\theta_{t}=(1+\gamma) \theta_{t-1}
$$

where $\gamma$ is the exogenous growth rate of $\theta$.

As already stated, we want to also allow for radical technological change in the form of the arrival and dissemination of a new production process. This radical technological change takes the form of the arrival of an alternative modern production process which depends on the same two factors but exhibits less decreasing returns to the accumulable factor, $K$, as follows.

$$
Y_{i, t}=\Phi_{t} K_{i, t}^{\beta}\left(\theta_{t} L_{i, t}\right)^{1-\beta} \text { with } 0<\alpha<\beta<1
$$

We interpret this alternative production process - or alternative form of work organization - as a General Purpose Technology that over time becomes a relevant means of production as $\phi$ becomes sufficiently high. In effect, we can consider that initially $\Phi=0$ and hence this technology is not operative. Conversely, as soon as $\Phi>0$, the firm faces a menu of available technologies to produce the same good. It therefore has to choose not only the amount of total factor it will use to achieve the production of output, but also how to allocate it between the two available technologies. In other words, technology adoption is an endogenous decision of the firm. Hence, with a $T$ and $M$ superscript denoting respectively the traditional and modern means of production, the problem of a firm amounts to solving the following problem.

$$
\max _{\left\{L_{i, t}, K_{i, t}, Y_{i, t}^{\tau}, L_{i, t}^{\tau}, K_{i, t}^{\tau} ; \tau=T, M\right\}} Y_{i, t}^{T}+Y_{i, t}^{M}-W_{i, t} L_{i, t}-z_{i, t} K_{i, t}
$$

s.t

$$
\begin{aligned}
& Y_{i, t}^{T}=K_{i, t}^{T^{\alpha}}\left(\theta_{t} L_{i, t}^{T}\right)^{1-\alpha} \\
& Y_{i, t}^{M}=\Phi_{t} K_{i, t}^{M^{\beta}}\left(\theta_{t} L_{i, t}^{M}\right)^{1-\beta} \\
& L_{i, t}=L_{i, t}^{T}+L_{i, t}^{M}
\end{aligned}
$$

\footnotetext{
${ }^{18}$ Throughout this section, we rely on a broad definition of capital which amounts to interpret it as an aggregate of both human and physical capital. Since there is a large class of models where an explicit modelling of human and physical capital leads to a reduced-form in which human and physical capital actually act as an aggregate (see for example Barro and Sala-i-Martin (1995)), the approach is not overly restrictive. However, since the appropriateness of such an interpretation may not be entirely transparent and in order to check the robustness of our results, in the following section we extent the model to explicitly distinguish between human capital — which is traded domestically — and physical capital — which is traded on an international market.
} 


$$
\begin{aligned}
& K_{i, t}=K_{i, t}^{T}+K_{i, t}^{M} \\
& L_{i, t} \geqslant 0, K_{i, t} \geqslant 0, Y_{i, t}^{\tau} \geqslant 0, L_{i, t}^{\tau} \geqslant 0, K_{i, t}^{\tau} \geqslant 0 ; \tau=\{T, M\}
\end{aligned}
$$

where $W_{i, t}$, the price of unskilled labor in economy $i$, and $z_{i, t}$, the corresponding rental price of capital, are taken as given by the firm. To understand the implications of technological adoption, it is helpful to conceptually view the firm's decision problem as divided into two phases. First, for given levels of $K$ and $L$, the firm must decide on what technology, or mix of technologies, to adopt. Second, given the resulting optimal technological adoption decision, the firm can decide on the optimal level for $K$ and $L$. The following proposition characterizes the first stage of this decision process, that is, the optimal technological adoption decision.

Proposition 1 For given levels of $K$ and $L$, the firm's technological adoption decision takes the following form:

i. if $\frac{K_{i, t}}{\theta_{t} L_{i, t}}<\Omega_{t}^{T}$ then only the traditional technology is adopted;

ii. if $\Omega_{t}^{T}<\frac{K_{i, t}}{\theta_{t} L_{i, t}}<\Omega_{t}^{M}$ then both the modern technology and the traditional technology are in use;

iii. if $\frac{K_{i, t}}{\theta_{t} L_{i, t}}>\Omega_{t}^{M}$ then only the modern technology is adopted.

where

$$
\Omega_{t}^{T}=\Phi_{t}^{\frac{1}{\alpha-\beta}}\left(\frac{\alpha}{\beta}\right)^{\frac{\beta}{\beta-\alpha}}\left(\frac{1-\alpha}{1-\beta}\right)^{\frac{1-\beta}{\beta-\alpha}}
$$

and

$$
\Omega_{t}^{M}=\Phi_{t}^{\frac{1}{\alpha-\beta}}\left(\frac{\alpha}{\beta}\right)^{\frac{\alpha}{\beta-\alpha}}\left(\frac{1-\alpha}{1-\beta}\right)^{\frac{1-\alpha}{\beta-\alpha}}
$$

Proof: See appendix A.1.

Proposition 1 indicates that if the capital-labor ratio, $\frac{K}{\theta L}$, is sufficiently low relative to $\Phi_{t}$, then it is optimal to only use the traditional technology. Alternatively, if it is sufficiently high, then is it optimal to use only the modern technology. Finally, if $\frac{K}{\theta L}$ is in the right ratio relative to $\Phi_{t}$, then it is optimal to use both technologies simultaneously. As we shall show, equilibrium forces will cause the last regime to be operative over an extended period of time. We will refer to this latter regime, where both technologies are operative, as the adoption phase. 
A conceptually important implication that results from the adoption decision is summarized in the following proposition.

Proposition 2 During the adoption phase, aggregate technology is of the form $A K+B \theta L$.

Proof: See appendix A.2.

In other words, proposition 2 indicates that the adoption phase corresponds to aggregate technology with an AK type structure - more precisely an $A K+B \theta L$ structure. In effect, during this phase, a change in $\frac{K}{\theta L}$ implies a reallocation of capital and labor between the two technologies, thereby avoiding the effects of decreasing returns. These two propositions are illustrated in figure 4, which reports the output-per-worker as a function of capitalper-worker, both for the traditional and modern technologies. The thick line corresponds to the aggregate technology implied by the optimal adoption regime. As can be seen from this figure, the linear part of the technology only arises for capital-labor ratios between $\underline{k}$ and $\bar{k}$.

Figure 4: Technology

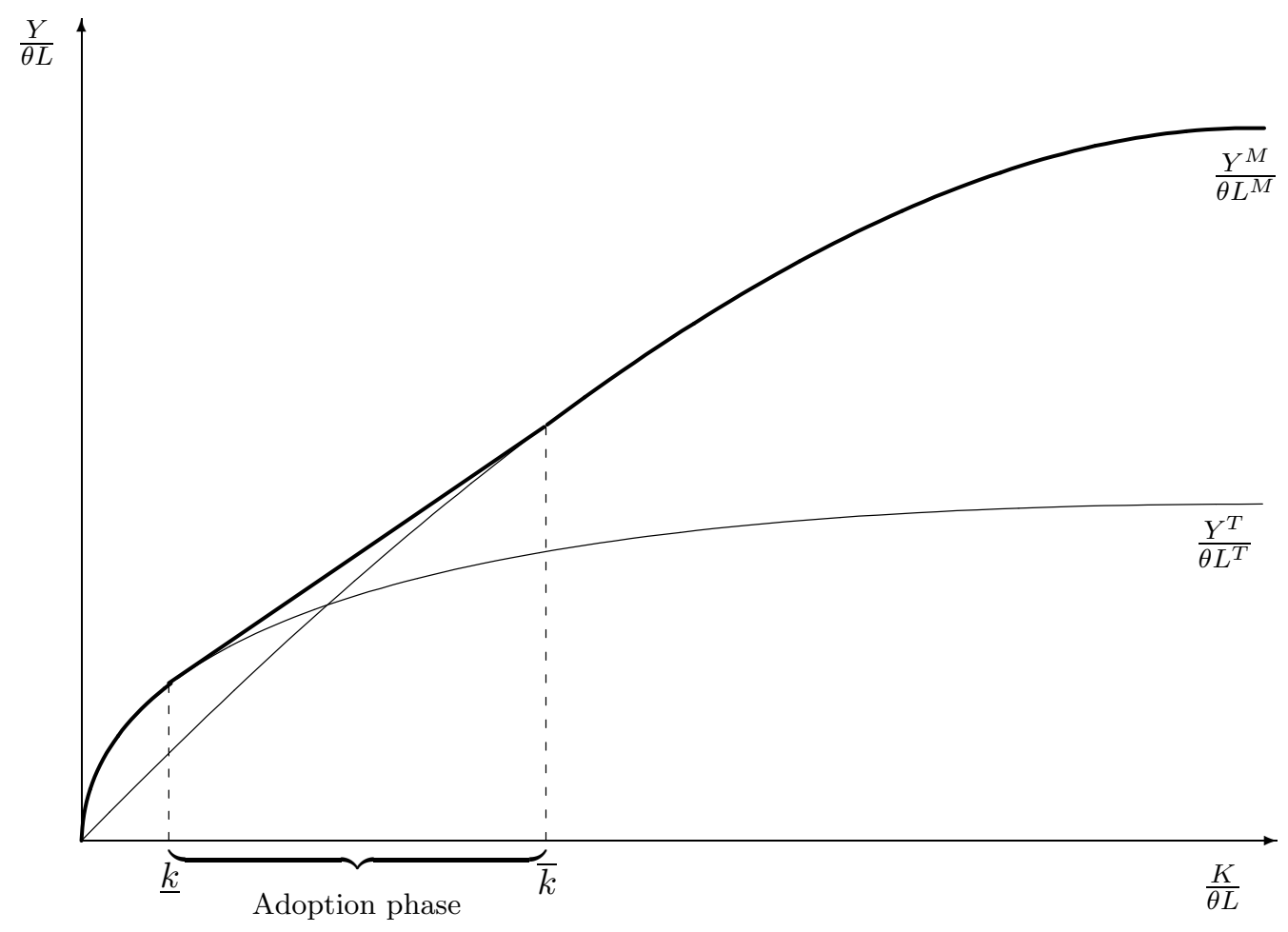

The firm's complete decision problem gives rise to a demand function for labor and a 
demand function for capital, and thereby characterizes the demand side of the market. On the supply side, we assume that the market for unskilled labor is a domestic market with the supply determined entirely by domestic households. In contrast, we assume that households supply capital to an international market and that it is financial intermediaries that allocate the internationally available capital to domestic firms. Hence, to complete the description of the economy, we need to specify the objectives and the behavior of households and financial intermediaries.

\subsubsection{Household}

For simplicity, households are assumed to live for one period and have a bequest motive that leads to savings. Moreover, in each period there is the birth of a new cohort of households. In the theoretical section of the paper, we could let households live for an arbitrary number of periods instead of assuming they live only for one period. However, for the quantitative analysis, it is helpful to adopt the metaphor of one period lived households with bequest motives in order to generate simple savings behavior. To this end, we let households have preferences over current consumption and have a bequest motive directed towards their replacement cohort. In economy $i$, the relative size of the new cohort is such that the rate of population growth for this economy is $\eta_{i}$. Note that in the model, labor force growth, employment growth and population growth are interchangeable terms.

In the one period of life, a household supplies one unit of labor to the market and therefore receives the real wage, $w_{i, t}$, to compensate for her work. She also receives profits from financial intermediaries, $\pi_{i, t}$, and a bequest, $b_{i, t}$, left by generation $t-1$ to members of generation $t$. These revenues are then used to consume, $c_{i, t}$ and save $s_{i, t}$. Therefore, the household faces a budget constraint of the form

$$
c_{i, t}+s_{i, t}=w_{i, t}+\pi_{i, t}+\frac{b_{i, t}}{1+\eta_{i}}
$$

Savings will be transmitted to the next cohort in the form of a bequest after the application of the international real interest rate $r_{t+1}$, and we therefore have

$$
b_{i, t+1}=s_{i, t}\left(1+r_{t+1}\right)
$$

The household decides on how much to consume, save and leave to the next cohort so as to maximize her utility

$$
\max _{\left\{c_{i, t}, s_{i, t}, b_{i, t+1}\right\}} U\left(c_{i, t}\right)+V\left(b_{i, t+1}\right)
$$

subject to (3.1) and (3.2). 


\section{$3.2 \quad$ Financial intermediaries}

Financial intermediaries make profits by borrowing capital from the international market, at rate $r_{t}$, and renting it to firms at a net rate of $z_{i, t}-\delta$, where $\delta$ is the rate of depreciation of capital. In the absence of any transaction costs, competition between financial intermediaries would drive the price of capital to firms to $r_{t}+\delta$. However, we assume that intermediation involves a cost $\nu_{i, t}$. In particular, we view this intermediation cost as a type of adjustment cost which increases with the size of new capital flows. ${ }^{19}$ Furthermore, we assume that the marginal intermediation cost is taken as exogenous from the view point of an intermediary and hence, competition assures that the cost of capital to domestic firms is given by:

$$
z_{i, t}=r_{t}+\delta+\nu_{i, t}
$$

With an adjustment cost interpretation in mind, we assume that the marginal intermediation cost, $\nu_{i, t}$, takes the following form

$$
\nu_{i, t}= \begin{cases}0 & \text { if } K_{i, t} \leqslant K_{i, t-1} \\ \nu\left(\frac{K_{i, t}-K_{i, t-1}}{K_{i, t-1}}\right) & \text { if } K_{i, t}>K_{i, t-1}\end{cases}
$$

where $K_{i, t}$ is the aggregate flow of capital to country $i$ and where $\nu(\cdot)$ is an increasing function. Note that given this form for the marginal intermediation costs, the total cost associated with intermediation in country $i$ is ${ }^{20}$

$$
\Upsilon_{i, t}=\int_{K_{i, t-1}}^{K_{i, t}} \nu\left(\frac{x-K_{i, t-1}}{K_{i, t-1}}\right) \mathrm{d} x
$$

\subsection{Equilibrium}

An equilibrium for this economy consists of a sequence of prices $\left\{r_{t}, w_{i, t}, z_{i, t} ; i=1, \ldots, N\right\}_{t=0}^{\infty}$ and allocations $\left\{K_{i, t}^{T}, K_{i, t}^{M}, L_{i, t}^{T}, L_{i, t}^{M}, s_{i, t} ; i=1, \ldots, N\right\}_{t=0}^{\infty}$ such that,

\footnotetext{
${ }^{19}$ The assumption that there are frictions limiting international capital movements is consistent with the evidence reviewed in Obstfeld and Rogoff (2000).

${ }^{20}$ The profits of financial intermediaries made in country $i$ are $\nu_{i, t} K_{i, t}$ minus the total intermediation costs. Indeed, we can actually think of the intermediary as solving the following program taking $K_{i, t-1}$ as given:$$
\max _{K_{i, t}} z_{i, t} K_{i, t}-\left(r_{t}+\delta\right) K_{i, t}-\int_{K_{i, t-1}}^{K_{i, t}} \nu\left(\frac{x-K_{i, t-1}}{K_{i, t-1}}\right) \mathrm{d} x
$$

An alternative interpretation of the model is one where firms face a capital adjustment cost, but where firms act myopically by only internalizing the current adjustment cost when deciding on current investment. Although it may be desirable to have firms or financial intermediaries completely internalize the costs associated with changing the stock of capital, such a modification greatly increase the complexity of the model without any apparent gains in insight.
} 
$i$ given $\left\{w_{i, t}, z_{i, t}\right\}_{t=0}^{\infty},\left\{K_{i, t}^{T}, K_{i, t}^{M}, L_{i, t}^{T}, L_{i, t}^{M}\right\}_{t=0}^{\infty}$ solves the firms problem.

ii. given $\left\{w_{i, t}, r_{t}\right\}_{t=0}^{\infty},\left\{s_{i, t}\right\}_{t=0}^{\infty}$ solves the consumers problem.

iii. there exist no unexploited gains from trade in capital intermediation, that is, $z_{i, t}=$ $r_{t}+\delta+\nu\left(\frac{K_{i, t}-K_{i, t-1}}{K_{i, t-1}}\right)$

$i v$. The markets for labor and capital clear, that is,

$$
\begin{aligned}
& L_{i, t}^{T}+L_{i, t}^{M}=L_{i, 0}\left(1+\eta_{i}\right)^{t}, \text { for } t \geqslant 0 \text { and } i=1, \ldots, N \\
& \sum_{i=1}^{N}\left(K_{i, t}^{T}+K_{i, t}^{M}\right)=\sum_{i=1}^{N} L_{i, t-1} s_{i, t-1}, \text { for } t \geqslant 0
\end{aligned}
$$

\subsection{Basic properties}

In order to highlight how the arrival of an alternative production process leads to departure from the standard Solow growth model, we first want to emphasize some basic properties of our model that relates to the determinants of cross-sectional outcomes in the absence of technological choice. In particular, as stated in proposition 3, in the absence of technological choice, our international model shares two central properties with the traditional Solow growth model: these are convergence and the presence of a negative effect of labor force growth on productivity growth. ${ }^{21}$

Proposition 3 In the absence of the alternative technology $\left(\Phi_{t}=0\right)$, cross-country growth in output-per-worker will exhibit

i. a negative relationship with the initial level of output-per-worker, that is, it will exhibit convergence;

ii. a negative relationship with the rate of labor force growth $\eta_{i}$, where the magnitude of this effect is smaller than $\alpha$

Proof: See appendix A.3.

The main equilibrium forces underlying proposition 3 can be seen from the allocation condition for capital which equates the marginal product of capital, $z_{i, t}=\alpha\left(\frac{K_{i, t}}{\theta_{t} L_{i, t}}\right)^{\alpha-1}$, to

\footnotetext{
${ }^{21}$ It is well known that an international version of the Solow model with adjustment costs to capital generates the properties of convergence and the negative effects of population growth on labor productivity growth. See for example Barro-Sala-i-Martin (1995).
} 
the rental cost of capital inclusive of intermediation costs. In equilibrium, this relationship is given by

$$
r_{t}+\delta+\nu\left(\gamma_{i, t}^{k}\right)=\alpha\left(\frac{Y_{i, t-1}}{L_{i, t-1}}\right)^{\frac{\alpha-1}{\alpha}}\left(\frac{1+\gamma_{i, t}^{k}}{\theta_{t}\left(1+\eta_{i}\right)}\right)^{\alpha-1}
$$

where $\gamma_{i, t}^{k}=\left(K_{i, t}-K_{i, t-1}\right) / K_{i, t-1}$ denotes the rate of growth of capital. In effect, the above equation can be seen as determining the cross-sectional distribution of growth rates of capital for a given world interest rate. From this relationship, it is easy to see that the rate of growth of capital for a country is a decreasing function of its initial level of output-perworker. This allocation rule for capital thereby causes output growth in the model to exhibit convergence, that is, higher initial labor productivity is associated with lower subsequent growth in output-per-worker. Moreover, from the above relationship, we can see that the rate of growth of capital will be positively related to labor force growth. However, this latter effect will not be sufficiently strong to offset the direct negative effect of labor force growth on capital deepening. Hence, in our model, labor productivity grows more slowly in a high population growth economy even though international capital mobility allows such a country to attract more capital.

We are now in a position to examine how the introduction of an alternative technology affects the equilibrium properties of the model. To this end, it is helpful to consider the behavior of the model in the case where all economies are in the adoption phase, that is, in the situation where they are simultaneously using both technologies.

Proposition 4 In the presence of the alternative technology, if all economies are in the adoption phase, then cross-country growth in output-per-worker over such a period

i. will not exhibit convergence, that is, there will not be a negative relationship between the initial level of output-per-worker and the growth in output-per-worker.

ii. will exhibit a negative relationship with the rate of labor force growth of a magnitude greater than $\alpha$.

Proof: See appendix A.4.

Proposition 4 indicates that the process of technological adoption following the dissemination of a new technology has the potential to significantly change the determinants of cross-country growth in labor productivity. In particular, proposition 4 highlights that when 
countries are in the adoption phase, there will no longer be forces directly favoring convergence of labor productivity, while there will be strong forces causing divergence in labor productivity due to difference in labor force growth. Hence, after the dissemination of a new general purpose technology, we are likely to observe a period of time where the speed of convergence decreases substantially and where the magnitude of the negative relationship between labor-force growth increases from something smaller than $\alpha$ to something greater than $\alpha$. These effects, which would be consistent with the observations in 1 and 2 , should arise as more and more countries start transiting towards the new technology and thereby begin reflecting the properties emphasized in proposition 4. An interesting aspect of this proposition is that it gives quantitative insight with respect to how the introduction of a new technology may affect the negative relationship between labor force growth and labor productivity growth. For example, considering capital to be an aggregate of both human and physical capital, the results of Mankiw, Romer and Weil (1992) suggest that $\alpha$ is greater that 0.5 and possibly of the order of 0.7 . Therefore, proposition 4 can be interpreted as stating that the process of technological transition could cause the tradeoff between labor productivity growth and labor force growth to increase from somewhere between zero and 0.5 to a magnitude greater than 0.6 or 0.7 , which is precisely that observed in figures 1 and $2 . .^{22}$

In order to understand proposition 4 , it is helpful to distinguish two mechanisms driving the result. The first mechanism relates to how the introduction of a new technology affects each country's production possibility set. The second mechanism relates to how capital flows are determined when countries are in the adoption phase. It is the combination of both these mechanism which lie behind proposition 4 .

In terms of the production possibility set, the introduction of a new technology has important implications. When firms have a choice between two technologies, the optimal adoption rule will lead them to convexify the possibility set and thereby cause the emergence of a linear segment in the aggregate production technology, that is, it causes the emergence of an $A K+B \theta L$ type structure as indicated in proposition 2. To see this, consider again figure 4 where we graph the two (traditional and modern) underlying technologies in intensive form (i.e. $Y / \theta L$ as a function of $K / \theta L)$. Given these two technologies, there is a range of capital labor ratios, $K / \theta L \in[\underline{k} ; \bar{k}]$, where it is optimal to use both production processes. Over this range, the marginal product of capital will not exhibit decreasing returns since this is avoided

\footnotetext{
${ }^{22}$ Since proposition 4 is mainly a qualitative statement, it does not tell us if the arrival of a new technology could actually reproduce the size and the timing of the changes observed in figures 1 and 2 . It is for this reason that we also provide a quantitative evaluation of the model.
} 
by reallocating factors between two techniques of production. Note that an improvement in the modern technology (through a change in $\Phi_{t}$ ) causes that $A K+B \theta L$ segment to shift to the left as it pivots upwards. It is interesting to note that, if a country were in autarky, and the new technology gradually improved in terms of increases in $\Phi_{t}$, then the economy would appear to leave a Solow regime with diminishing returns, and enter an AK type regime. Furthermore, during such a transition, an increase in $\Phi_{t}$ would cause the price of unskilled labor to decrease, while simultaneously leading to an increase in the returns to factors that can be accumulated.

In the case of internationally linked economies, the introduction of the new technology affects cross-sectional growth properties through its effect on the allocation of capital. If countries are in the adoption phase - in the $A K+B \theta L$ segment - then the marginal product of capital is equal to $\mathrm{A}$ in all these countries and the allocation of capital is driven by the equation

$$
r_{t}+\delta+\nu\left(\frac{K_{i, t}-K_{i, t-1}}{K_{i, t-1}}\right)=A \quad \forall i=1, \ldots, N
$$

therefore leading to

$$
\gamma_{i, t}^{k}=\nu^{-1}\left(A-r_{t}-\delta\right) \quad \forall i=1, \ldots, N
$$

Hence, in this phase, the growth rate of capital is equalized across country and thereby independent of both the country's initial level of labor productivity (within the relevant range) and the countries labor force growth. Accordingly, capital labor ratios grow slower in higher labor force growth countries by a proportionality factor of -1 , and are no longer driven by forces of convergence. This slower growth in capital labor ratio causes slower labor productivity growth in proportion to the income share of capital. Since the income share of capital along the technological transition is greater or equal to $\alpha$ (the share of capital in the traditional technology), this explains why such a technological transition can cause the tradeoff between employment growth and labor productivity growth to increase to the magnitude greater of $\alpha$. For example, if intermediation costs are very small, cross-sectional growth in labor productivity would exhibit no substantial tradeoff with labor force growth before the introduction of the new technology then, during the transition period, it would exhibit a tradeoff greater than $\alpha$, and finally, when (and if) the set of countries exit this phase, there will be a return to a situation where there is no significant tradeoff between labor force growth and labor productivity growth. 


\subsection{Quantitative Analysis}

Our theoretical analysis suggests that the patterns highlighted in figures 1 and 2 may reflect a technological transition which created a temporary AK accumulation phase, that is, a phase where the aggregate production technology has an $A K+B \theta L$ structure. In this section, we explore the plausibility of this explanation by examining whether our model, once quantified, can in effect reproduced the trends observed in figures 1 and 2. To this end, we begin by parameterizing our model, estimating the unknown parameters and then evaluating its performance.

Basic methodology: Since the model is to be evaluated on quantitative grounds, we have to specify functional forms for the utility function and the marginal intermediation cost. The utility function is assumed to take the form

$$
U(c)+V(b)=\log (c)+\psi \log (b)
$$

and the marginal intermediation cost is kept as simple as possible

$$
\nu(x)=\nu \cdot x
$$

Finally, we assume that $\Phi_{t}$ evolves over time as

$$
\Phi_{t+1}=(1+\varphi) \Phi_{t}
$$

with $\Phi_{0}>0$ given. $\varphi$ represents the rate of growth of the relative productivity in the modern technology. When $\varphi=0$, then total factor productivity in the modern technology does not increase faster than in the traditional technology. This will be taken as our benchmark experiment (experiment I). If we now assume that $\varphi>0$, then $\Phi_{t}$ grows at a constant rate and therefore complements the growth in labor efficiency at a constant pace.

This leaves us with 9 parameters to set: $\alpha, \beta, \delta, \nu, \psi, \gamma, \varphi, \Phi_{0}$ and $\theta_{0}$. Not all the parameters will be estimated, for identification sakes, $\delta$ is set such that capital depreciates at an annual rate of $6 \%(\delta=0.06)$. All other 8 parameters will be estimated: $\Theta=\left\{\alpha, \beta, \nu, \psi, \gamma, \varphi, \Phi_{0}, \theta_{0}\right\}$.

Our estimation strategy is based on a moment estimation method. The deep parameters are obtained in order to minimize the discrepancy between a set of moments obtained from the data and those obtained using the model. More specifically, we select the deep parameters of the model in order to replicate parameters from rolling regressions, as displayed in figure 1 and 2. Hence, our world economy will consist of the 18 countries $(N=18)$ considered in the 
empirical study (see section 2). The initial distribution of revenues - in terms of outputper-capita - and labor force growth $-\left\{\eta_{i} ; i=1 \ldots, N\right\}-$ are taken from the data. Since we are to replicate the magnitude and evolution of the effects of both labor force growth and initial conditions on productivity growth, we will attempt to replicate the 40 estimates $(2 \times 20)$ related to the rolling regressions over the period 1960-97 with a window size of 19 . Hence the estimation procedure exhibits a degree of over-identification of $32 .^{23}$

Given a set of moments (see the following section for the choice of the moments) and a set of policy functions for the variables of interest, we adopt the following indirect inference method to estimate parameters:

Step 1: Estimate a $q$-dimensional vector of moments (here $q=40), m \in \mathcal{M} \subset \mathbb{R}^{q}$, from the data. Hereafter, $\widehat{m}_{T}$ denotes the estimated moments obtained from section 2 .

Step 2: From the theoretical model, and given a vector of structural parameters, $\Theta$, a path for output-per-worker and labor force, denoted $\widetilde{\left(\frac{Y}{L}\right)}_{i, t}(\Theta), \tilde{L}_{i, t}(\Theta), \quad i=1, \ldots, N$, is performed in each country.

Step 3: From these simulations, we estimate the moments $\tilde{m}(\Theta)$, by running the same rolling regressions as in the data.

Step 4: An estimate $\tilde{\Theta}$ for $\Theta$ minimizes the quadratic form:

$$
J(\Theta)=\left(\widehat{m}_{T}-\tilde{m}(\Theta)\right)^{\prime} W_{T}\left(\widehat{m}_{T}-\tilde{m}(\Theta)\right)
$$

where $W_{T}$ is a symmetric nonnegative matrix defining the metric.

Steps 2 to 4 are conducted repeatedly until convergence - i.e. until a value of $\Theta$ that minimizes the objective function is obtained. From a practical point of view, the matrix $W_{T}$ is the inverse of the variance matrix of the empirical moments, which we form by feeding the diagonal with the variance of each estimated moment.

Two cases will be under study. In the first case, which will be labelled as experiment I, we set $\varphi=0$, therefore assuming that $\Phi_{t}$ is constant over time. The second experiment,

\footnotetext{
${ }^{23}$ In the model, labor force growth and population growth are identical. However, in the data they are not. Hence it is necessary to decide what is the more appropriate empirical counterpart to $\eta_{i}$ in the model. We believe that labor force growth is the better empirical counterpart and therefore we perform the quantitative exercise by comparing theoretical regressions using $\eta_{i}$ as a regressor with empirical regressions using labor force growth as a regressor. Note that when using labor force growth as a regressor, we instrument it with population growth as to minimize biases due to the potential endogeneity of participation decisions.
} 
labelled as experiment II, relaxes the last assumption therefore assuming that productivity in the modern means of production increases faster than in the traditional technology. Table 6 reports the results.

Table 6: Estimation results

\begin{tabular}{lrrr}
\hline \hline & Experiment I & Experiment II & Experiment III \\
\hline$\alpha$ & 0.48613 & 0.43433 & 0.46111 \\
$\beta$ & 0.65140 & 0.60673 & - \\
$\nu$ & 0.79581 & 1.07861 & 1.20023 \\
$\psi$ & 8.27543 & 8.23692 & 8.27543 \\
$\gamma$ & 0.00000 & 0.00016 & 0.00000 \\
$\Phi_{0}$ & 0.57800 & 0.36160 & - \\
$\theta_{0}$ & 14.52487 & 8.90931 & 14.52487 \\
$\varphi$ & - & 0.00431 & - \\
\hline $\mathrm{J}(\Theta)$ & 7.50700 & 3.80182 & 15.47780 \\
\hline \hline
\end{tabular}

A first interesting fact that emerges from table 6 is that the estimated value for $\alpha$ is reasonable in size, as we find a value close to 0.5 for both experiment under consideration. The value for $\beta$ is much above $\alpha$ as it lies between 0.60 and 0.65 in both experiment I and II, therefore supporting our view that the patterns highlighted in figures 1 and 2 may reflect the arrival of new means of production that exhibit lower diminishing returns to scale with respect to factors that can be accumulated. ${ }^{24}$ Another result worth noting is that the model does not need additional source of growth other than the labor force growth and the introduction of the modern technology to replicate the data, as $\gamma$, the rate of growth of labor augmenting progress $\theta_{t}$, is estimated to be essentially 0 in experiment I. $^{25}$

Figure 5 graphs the estimates from rolling regression obtained from the data (dark line) and the model (grey line). As can be seen from this figure, the moments generated by the model lie within the 1-standard deviation confidence interval associated to the empirical moments (dashed line). Therefore, our theoretical framework is capable of replicating statistically the empirical estimates from the rolling regressions (recall that the level of overidentification is 33 in expriment I and 31 in experiment II).

It is worth noting that the existence of an exogenous process affecting $\Phi_{t}$ - which implies

\footnotetext{
${ }^{24}$ Note that this result was obtained without imposing $\beta>\alpha$ during the estimation.

${ }^{25}$ Note that this actually does not reflect a problem of identification since the algorithm was feeded with different initial values for $\gamma$, and always get to the same value. In case of identification problems, $\gamma$ would have been stuck at its initial level.
} 
Figure 5: Rolling regressions

(a) Experiment I
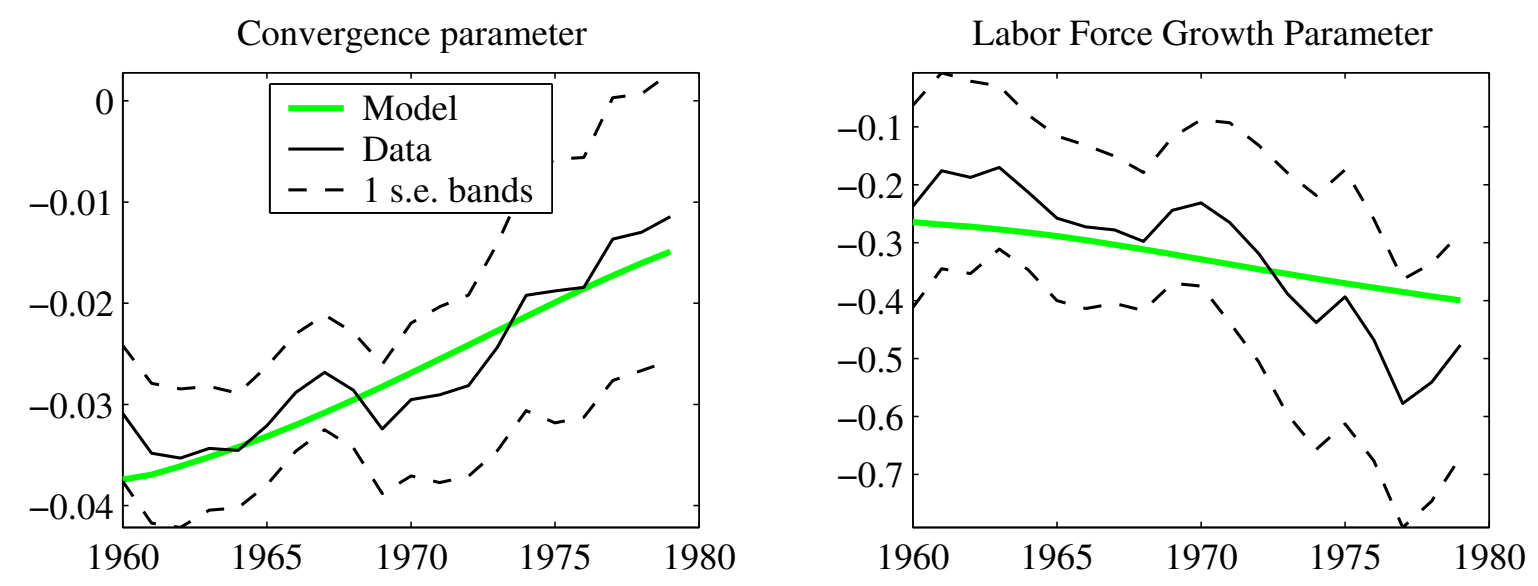

(b) Experiment II

Convergence parameter

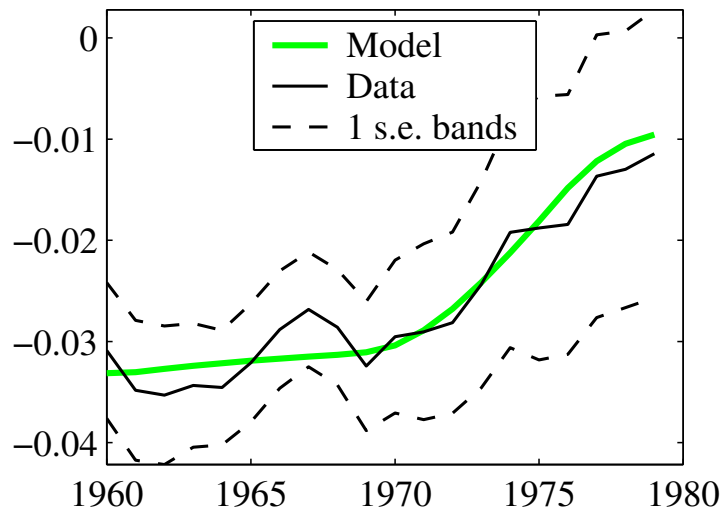

Labor Force Growth Parameter

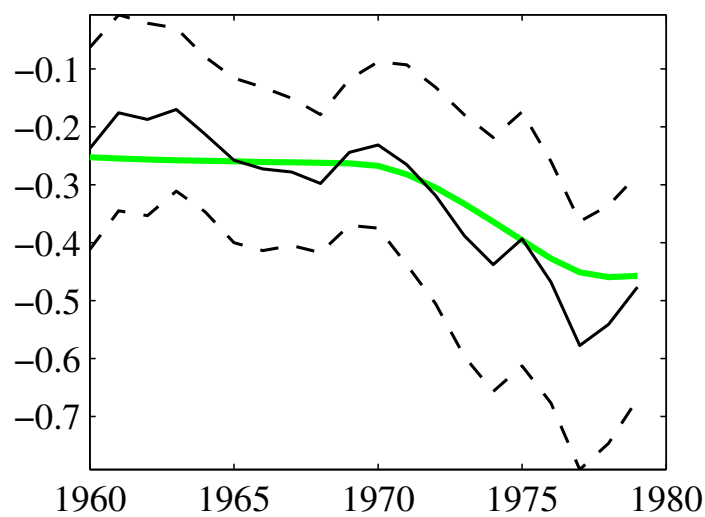


that the new technology becomes increasingly attractive over time- enhances the ability of the model to replicate the rolling regressions. It is worth noting that under experiment II, the gap between $\alpha$ and $\beta$ is slightly higher relative to experiment I, implying that the relative returns to factors that can be accumulated in the modern technology are marginally higher than in experiment I. This is accompanied by an increase in the marginal intermediation cost parameter, which rises from 0.80 to 1.10, implying for instance, that, assuming a rate of growth of capital of $3 \%$, the marginal intermediation costs increases from $2.39 \%$ in the first experiment to $3.24 \%$ in the second. Note that preferences are left unaffected by the introduction of a time varying $\Phi_{t}$, as $\psi$ - the weight attached to bequest in the utility function - is only marginally affected across the two experiments. In order to gauge the empirical relevance of such numbers, we report in table 7 the average annual rate of growth of world capital and the associated real interest rate. The numbers reported in the table indicate that the estimated parameters for the technology are quite consistent with the actual evidence on capital accumulation in the end of the twentieth century. Finally, in table 7, we also report the cross-country variance of $z$ (that is, the cross-country variance of the marginal product of capital $)^{26}$ as well as its average absolute deviation. Interestingly, the model produces differences in the marginal product of capital that appear of reasonable magnitude.

Table 7: Basic statistics

\begin{tabular}{lccc}
\hline \hline & Experiment I & Experiment II & Experiment III \\
\hline$\overline{\gamma_{k}}$ & $3.61 \%$ & $3.02 \%$ & $3.26 \%$ \\
$\bar{r}$ & $2.42 \%$ & $0.76 \%$ & $0.16 \%$ \\
$\sigma_{z}$ & $0.88 \%$ & $1.24 \%$ & $1.32 \%$ \\
$E|z-\bar{z}|$ & $0.69 \%$ & $0.97 \%$ & $1.03 \%$ \\
\hline \hline
\end{tabular}

In order to illustrate the functioning of the model, figure 6 illustrates a particular counterfactual where we shut down the adjustment costs (that is, we take the limit case as $\nu$ tends to 0 ), and we track the evolution of labor-productivity of the 18 economies over time as they adopt the new technology. ${ }^{27}$ Note that because $\nu$ is taken to zero, in the first (traditional) and third (modern) phases of the dynamics, the economies do not differ in there level of output-per-worker since capital mobility equalizes labor productivity across countries. As can be seen from the figure, as soon as they reach a high enough level of capital stock, the economies enter the adoption phase. The rate of growth of capital they experiment is equalized as they are in a zone where there are no decreasing returns to accumulation $(A K+B \theta L$ zone). This figure illustrates more particularly the first item of proposition 4 .

\footnotetext{
${ }^{26}$ We calculated this variance for each year, and took the average over the entire period.

${ }^{27}$ Note that productivity has been normalized by its initial level in this graph.
} 
In effect, when all economies are in the first phase, they converge to the same path. In contrast, when the economies enter the AK phase, the convergence process is stopped, as reflected by the divergent evolution of labor productivity. Note that even in this limit case where international capital mobility is becoming perfect, our model suggests that the set of countries would take about 15 years to go through the transition phase when $\alpha=0.486$ and $\beta=0.651$. The last experiment we conduct (experiment III) is aimed at illustrating that

Figure 6: Evolution of productivity without intermediation costs $(\nu=0)$

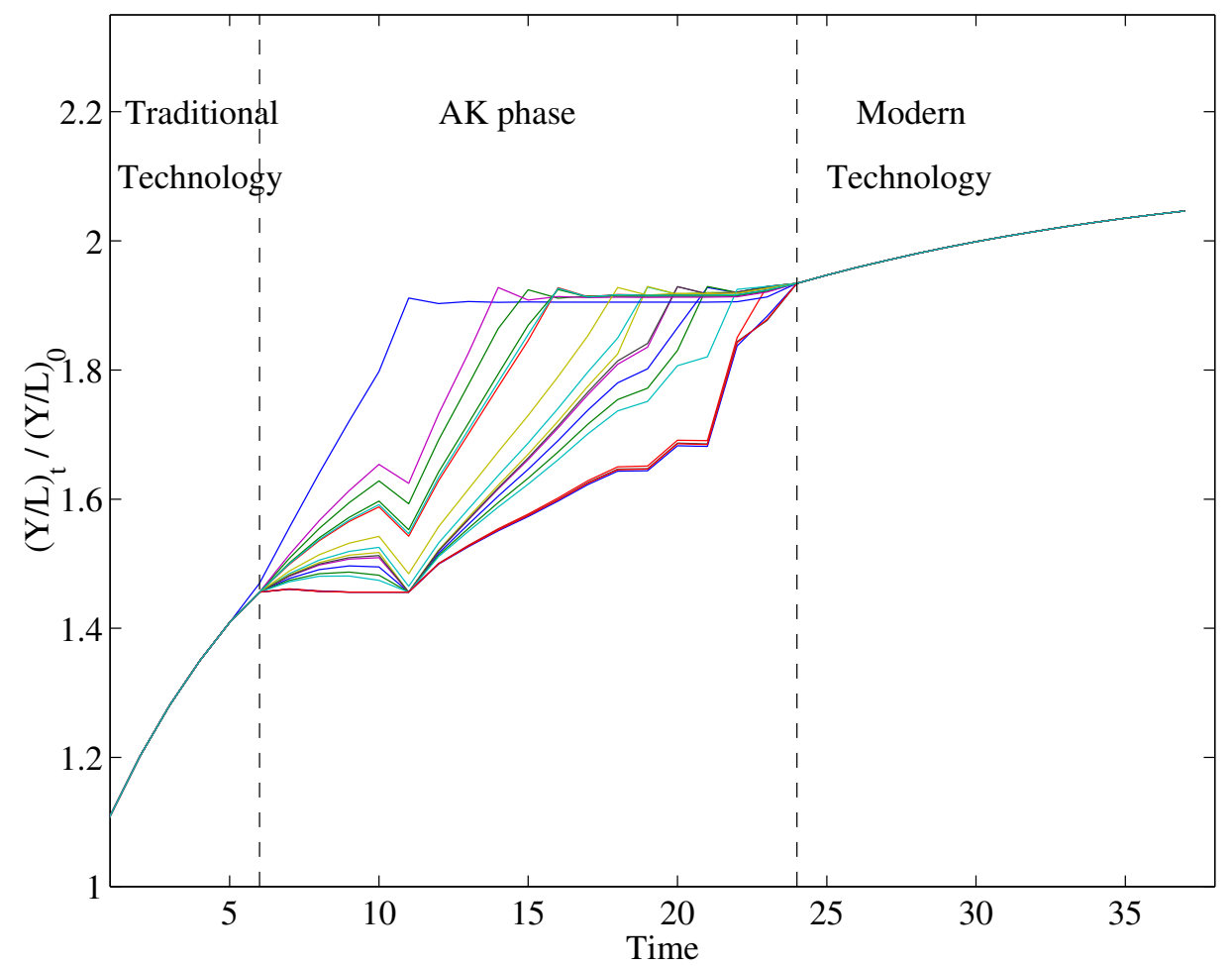

Note: Each line corresponds to the evolution of productivity of a given country, each country being characterized by a different rate of population growth.

we actually need to depart the standard growth model to explain the data. In particular, in experiment III we investigate what happens when only the traditional technology is available. The model is therefore estimated imposing $\Phi_{t}=0$ for all $t \geqslant 0$, implying that neither $\beta$ nor $\varphi$ are identifiable. ${ }^{28}$ As can be seen from the fourth column of table 6 , the value of the objective function is significantly and negatively affected by this assumption. In fact, as can be seen from figure 7 the model is unable to account for the variations in the parameters of the rolling regressions. Nevertheless, as predicted by proposition 3, the model generates a negative covariance between the rate of growth of labor and productivity growth on the one

\footnotetext{
${ }^{28}$ Due to identification problems, we estimated the model of experiment III with $\theta_{0}$ and $\psi$ set to their estimated level in experiment I.
} 
side, and a negative covariance between the initial conditions and productivity growth on the other side. But, the time pattern of these coefficients is flat. Therefore, it clearly appears

Figure 7: Rolling regressions

(a) Experiment III
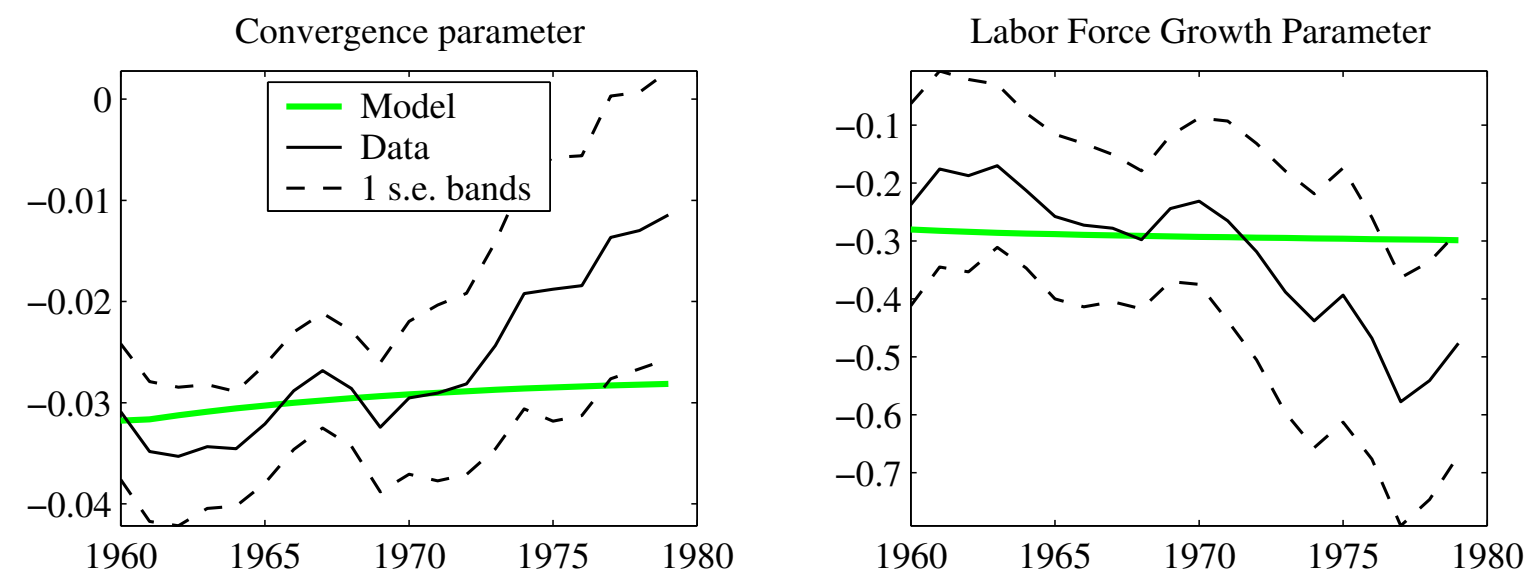

that the introduction of the modern technology is crucial to mimic the time varying pattern of the effects of labor force growth on productivity growth, and the convergence parameter.

\section{An Extended Model with Human and Physical Capital Ac- cumulation}

\subsection{The theoretical model}

\subsubsection{Technology}

Let us again consider a set of economies, indexed by $i=1, \ldots, N$, which all produce the same homogenous good, that can be either consumed or invested. Each firm in each country has access to the same technological possibilities. Initially, firms in all the countries produce output using the traditional production process which now depends on physical capital $K_{i, t}$, human capital $H_{i, t}$ and efficient units of unskilled labor $\theta_{t} L_{i, t}$ according to the following production function.

$$
Y_{i, t}=K_{i, t}^{\alpha_{k}} H_{i, t}^{\alpha_{h}}\left(\theta_{t} L_{i, t}\right)^{1-\alpha_{k}-\alpha_{h}}
$$

with $\alpha_{k} \in(0,1), \alpha_{h} \in(0,1)$ and $\alpha_{k}+\alpha_{h}<1$

As in the model of the previous section, we allow for factor augmenting technological 
change through growth in $\theta_{t}$, which is assumed to evolve as

$$
\theta_{t}=(1+\gamma) \theta_{t-1}
$$

where $\gamma$ is the exogenous growth rate of $\theta$.

As already stated, the model takes into account the possibility of a more radical technological change in the form of the arrival and dissemination of a new production process, which takes the form of an alternative modern production process which depends on the same three factors but exhibits less decreasing returns to the accumulable factors $K$ and $H$.

$$
Y_{i, t}=\Phi_{t} K_{i, t}^{\beta_{k}} H_{i, t}^{\beta_{h}}\left(\theta_{t} L_{i, t}\right)^{1-\beta_{k}-\beta_{h}}
$$

with $\beta_{k} \in(0,1), \beta_{h} \in(0,1)$ and $0<\alpha_{k}+\alpha_{h}<\beta_{k}+\beta_{h}<1$

With a $T$ and $M$ superscript denoting respectively the traditional and modern means of production, the problem of a firm amounts to solve

$$
\max _{\left\{L_{i, t}, K_{i, t}, H_{i, t}, Y_{i, t}^{\tau}, L_{i, t}^{\tau}, K_{i, t}^{\tau}, H_{i, t}^{\tau} ; \tau=T, M\right\}} Y_{i, t}^{T}+Y_{i, t}^{M}-W_{i, t} L_{i, t}-z_{i, t} K_{i, t}-q_{i, t} H_{i, t}
$$

s.t

$$
\begin{aligned}
& Y_{i, t}^{T}=K_{i, t}^{\alpha^{\alpha_{k}}} H_{i, t}^{\alpha_{h}}\left(\theta_{t} L_{i, t}^{T}\right)^{1-\alpha_{k}-\alpha_{h}} \\
& Y_{i, t}^{M}=\Phi_{t} K_{i, t}^{M \beta_{k}} H_{i, t}^{M^{\beta_{h}}}\left(\theta_{t} L_{i, t}^{M}\right)^{1-\beta_{k}-\beta_{h}} \\
& L_{i, t}=L_{i, t}^{T}+L_{i, t}^{M} \\
& K_{i, t}=K_{i, t}^{T}+K_{i, t}^{M} \\
& H_{i, t}=H_{i, t}^{T}+H_{i, t}^{M} \\
& L_{i, t} \geqslant 0, K_{i, t} \geqslant 0, H_{i, t} \geqslant 0, Y_{i, t}^{\tau} \geqslant 0, L_{i, t}^{\tau} \geqslant 0, K_{i, t}^{\tau}, H_{i, t}^{\tau} \geqslant 0 ; \tau=\{T, M\}
\end{aligned}
$$

where $W_{i, t}$, the price of unskilled labor in economy $i$, and $z_{i, t}$, the corresponding rental price of capital, and $q_{i, t}$ the price of human capital are taken as given by the firm.

\subsubsection{Household}

Like in our benchmark model, household are assumed to live for one period, and in each period there is the birth of a new cohort of households. Household have preferences over current consumption and have a bequest motive directed towards their replacement cohort. In economy $i$, the relative size of the new cohort is such that the rate of population growth for this economy is $\eta_{i}$. 
At time $t$, each household receives from the previous generation a transfer in the form of physical capital, denoted $s_{i, t-1}$, and a transfer in the form of human capital, denoted $x_{i, t-1}$. Furthermore, the household receives its share of profits from financial intermediaries, which is denoted $\pi_{i, t}$. The household supplies inelastically to the domestic market both its unskilled labor and its human capital as to receive total wage income equal to $w_{i, t}+x_{i, t-1} q_{i, t}$; where $W_{i, t}$ is the price of unskilled labor and $q_{i, t}$ is the rental price of human capital. The household supplies its inherited physical capital to the international capital market as to receive total physical capital income $s_{i, t-1}\left(1+r_{t}\right)$. The household uses its total revenues to consume, $c_{i, t}$ and save for each member of its replacement cohort, where savings can be in the form of either human capital $\left(x_{i, t}\right)$ or physical capital $\left(s_{i, t}\right)$. Therefore, the household faces a budget constraint that takes the following form.

$$
c_{i, t}+\left(s_{i, t}+x_{i, t}\right)\left(1+\eta_{i}\right)=w_{i, t}+q_{i, t} x_{i, t-1}+\left(1+r_{t}\right) s_{i, t-1}+\pi_{i, t}
$$

The total value of the bequest left by a household at time $t$ is expressed as follows.

$$
b_{i, t+1}=\left(s_{i, t}\left(1+r_{t+1}\right)+q_{i, t+1} x_{i, t}\right)\left(1+\eta_{i}\right)
$$

The household decides on how much to consume and save as to maximize her utility

$$
\max _{\left\{c_{i, t}, s_{i, t}, x_{i, t}, b_{i, t+1}\right\}} U\left(c_{i, t}\right)+V\left(b_{i, t+1}\right)
$$

subject to (4.3) and (4.4).

\subsubsection{Equilibrium}

The behavior of financial intermediaries is essentially the same as the one described in the previous section. Therefore, an equilibrium for this economy consists of a sequence of prices $\left\{r_{t}, w_{i, t}, z_{i, t}, q_{i, t} ; i=1, \ldots, N\right\}_{t=0}^{\infty}$ and allocations $\left\{K_{i, t}^{T}, K_{i, t}^{M}, L_{i, t}^{T}, L_{i, t}^{M}, H_{i, t}^{T}, H_{i, t}^{M}, s_{i, t}, x_{i, t} ; i=\right.$ $1, \ldots, N\}_{t=0}^{\infty}$ such that,

$i$. given $\left\{w_{i, t}, z_{i, t}, q_{i, t}\right\}_{t=0}^{\infty},\left\{K_{i, t}^{T}, K_{i, t}^{M}, L_{i, t}^{T}, L_{i, t}^{M}, H_{i, t}^{T}, H_{i, t}^{M}\right\}_{t=0}^{\infty}$ solves the firms problem.

ii. given $\left\{w_{i, t}, q_{i, t}, r_{t}\right\}_{t=0}^{\infty},\left\{s_{i, t}, x_{i, t}\right\}_{t=0}^{\infty}$ solves the consumers problem.

iii. there exist no unexploited gains from trade in capital intermediation, that is, $z_{i, t}=$ $r_{t}+\delta+\nu\left(\frac{K_{i, t}-K_{i, t-1}}{K_{i, t-1}}\right)$ 
$i v$. The markets for labor, human and physical capital clear, that is,

$$
\begin{aligned}
& L_{i, t}^{T}+L_{i, t}^{M}=L_{i, 0}\left(1+\eta_{i}\right)^{t}, \text { for } t \geqslant 0 \text { and } i=1, \ldots, N \\
& H_{i, t}^{T}+H_{i, t}^{M}=L_{i, t} x_{i, t-1}, \text { for } t \geqslant 0 \text { and } i=1, \ldots, N \\
& \sum_{i=1}^{N}\left(K_{i, t}^{T}+K_{i, t}^{M}\right)=\sum_{i=1}^{N} L_{i, t} s_{i, t-1}, \text { for } t \geqslant 0
\end{aligned}
$$

\subsection{Quantitative analysis}

In this section we assess the potential quantitative gains pertaining to the disaggregation of capital between human and physical capital. The quantitative evaluation of the model relies on the same methodology as the one used in the previous section. In particular, we maintain the same assumptions on the specification of utility and marginal intermediation cost. Table 8 reports the estimation results for our two benchmark experiments: experiment I assumes a constant $\Phi_{t}$ and experiment II assumes a growing $\Phi_{t}$.

Table 8: Estimation results

\begin{tabular}{lrr}
\hline \hline & Experiment I & Experiment II \\
\hline$\alpha_{k}$ & 0.38103 & 0.37448 \\
$\beta_{k}$ & 0.42939 & 0.37448 \\
$\alpha_{h}$ & 0.21649 & 0.15267 \\
$\beta_{h}$ & 0.27341 & 0.26669 \\
$\nu$ & 1.84987 & 2.24889 \\
$\psi$ & 8.54395 & 8.49798 \\
$\gamma$ & 0.00000 & 0.04612 \\
$\Psi_{0}$ & 0.78832 & 0.74907 \\
$\theta_{0}$ & 8.97477 & 6.31667 \\
$\varphi$ & - & 0.00295 \\
\hline $\mathrm{J}(\Theta)$ & 5.55070 & 3.47295 \\
\hline \hline
\end{tabular}

As should be expected, the objective function is lower than in our previous model, as disaggregation of capital between human and physical capital adds two parameters to the model $\alpha_{h}$ and $\beta_{h}$ and therefore brings in additional flexibility in the model and potential informational in the estimation. The model still supports our view that the empirical facts may reflect the arrival of new means of production exhibiting lower diminishing returns to scale with respect to factors that can be accumulated. Indeed, in the two experiments, we obtain a value for $\alpha_{k}+\alpha_{h}$ lying between 0.50 and 0.60 , while $\beta_{k}+\beta_{h}$ lies within the interval 0.65-0.70. Note for instance, that under experiment I, not only does the sum $\alpha_{k}+\alpha_{h}<\beta_{k}+\beta_{h}$ 
but we also get $\alpha_{h}<\beta_{h}$, reflecting the fact that the new means of production display less diminishing returns to human capital. It is also worth noting that the value of $\alpha_{k}$ and $\beta_{k}$ are about the same ${ }^{29}$ and more remarkably are both about 0.40 which corresponds approximately to the share of capital in value added in industrialized economies. Also note that disaggregating capital does not affect the value of $\psi$ - the preference parameter which remains close to the estimated value obtained in our benchmark model. It is however worth reporting that the marginal intermediation costs has risen compared to the previous model, in which case the intermediation costs affected the aggregate accumulable factor, while it now only affects physical capital. One final aspect to note from Table 8 is that, in Experiment II, the nature of the technological change inferred by imposing our model on the data is essentially a "skilled biased technological change", that is, our estimates suggests that the main characteristic of the new technology is its greater human capital intensity. ${ }^{30}$ In effect, our estimate of $\beta_{k}$ in Experiment II is identical to our estimate of $\alpha_{k}$.

Figure 8 reports the rolling regression obtained from the data (dark line) and the model (grey line). As can be seen from this figure, the model replicates both the pattern and the level of the parameters of the rolling regressions. In particular, the model can account remarkably well for the diminishing convergence parameter across the sample. Further, it appears that, compared to our benchmark model, splitting capital between human and physical capital enhances the ability of the theoretical model to mimic the increasing effect of labor force growth on labor productivity growth, and it is particularly consistent with Jorgensen and Yip (1999) estimate the growth in physical capital among G7 countries, which average between 4 and $6 \%$ over the period 1960-95. It should however be noted that this is obtained at a higher real interest rate and a higher cross-country variance of $z$, as reflected in table 9 .

Table 9: Basic statistics

\begin{tabular}{lcc}
\hline \hline & Experiment I & Experiment II \\
\hline$\overline{\gamma_{k}}$ & $4.57 \%$ & $6.71 \%$ \\
$\bar{r}$ & $10.11 \%$ & $8.44 \%$ \\
$\sigma_{z}$ & $2.46 \%$ & $3.12 \%$ \\
$E|z-\bar{z}|$ & $1.92 \%$ & $2.43 \%$ \\
\hline \hline
\end{tabular}

To gauge the timing of events, figure 9 reports the number of countries in each phase (traditional, adoption, modern production process) over time, therefore illustrating the dy-

\footnotetext{
${ }^{29}$ In this version of the model we imposed $\alpha_{k} \leqslant \beta_{k}$ during the estimation phase in order to assure convergence of our estimation method.

${ }^{30}$ Such an observation is consistent with the view that recent technological change across industrialized countries has been mostly skill-biased. See for example: Berman, Bound and Machin (1998).
} 
Figure 8: Rolling regressions

(a) Experiment I
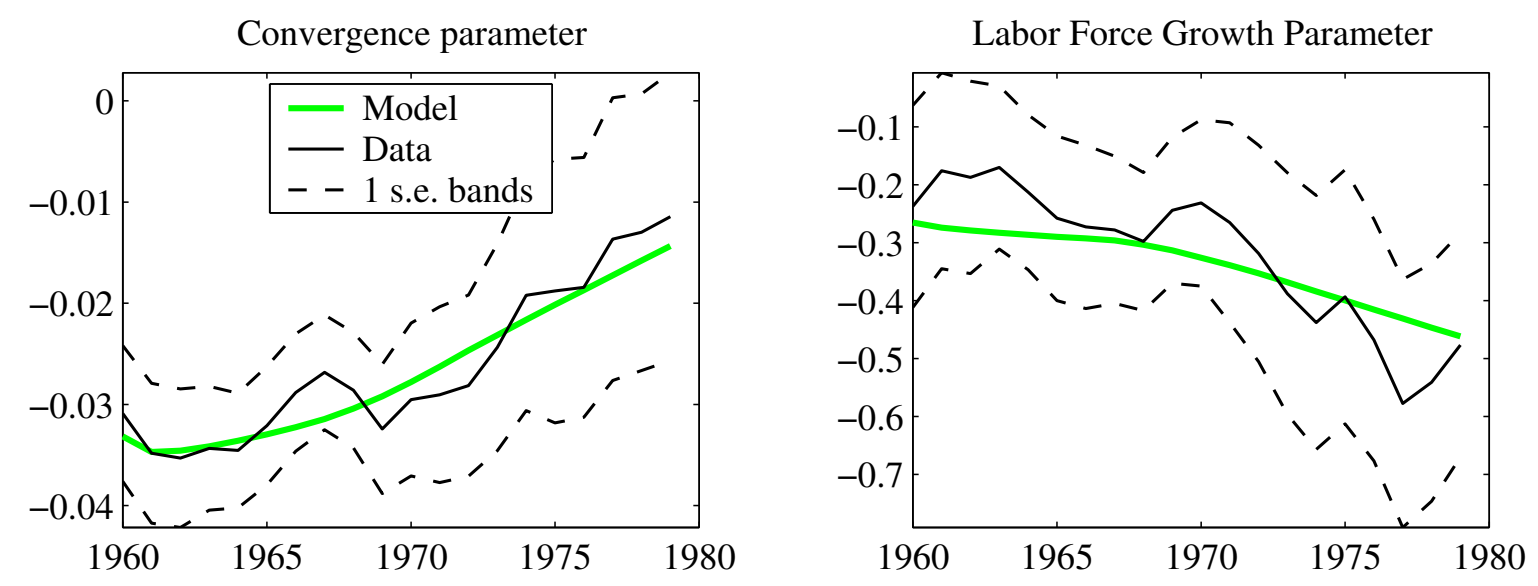

(b) Experiment II

Convergence parameter

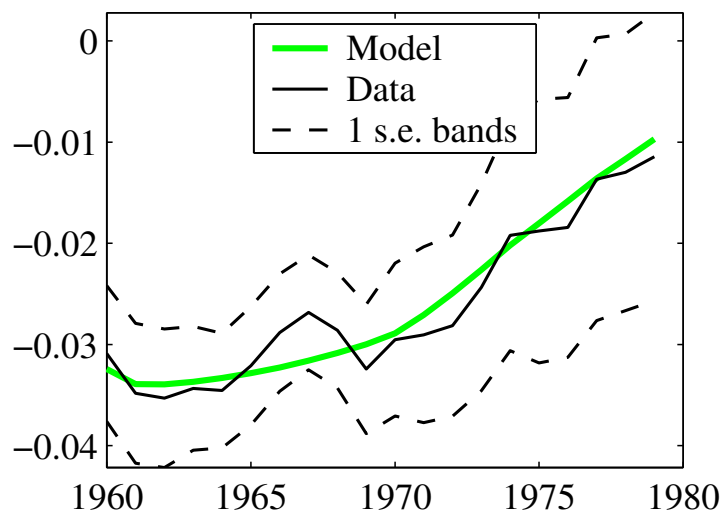

Labor Force Growth Parameter

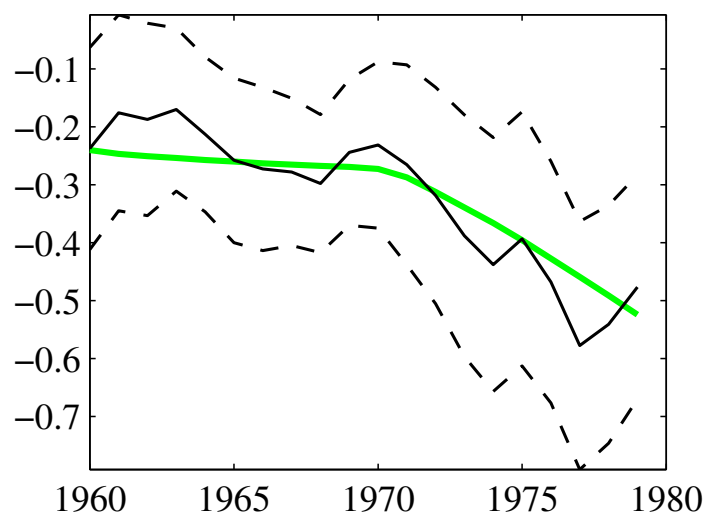


namics of the adoption process across countries. As can be seen, the adoption process starts

Figure 9: Adoption Dynamics
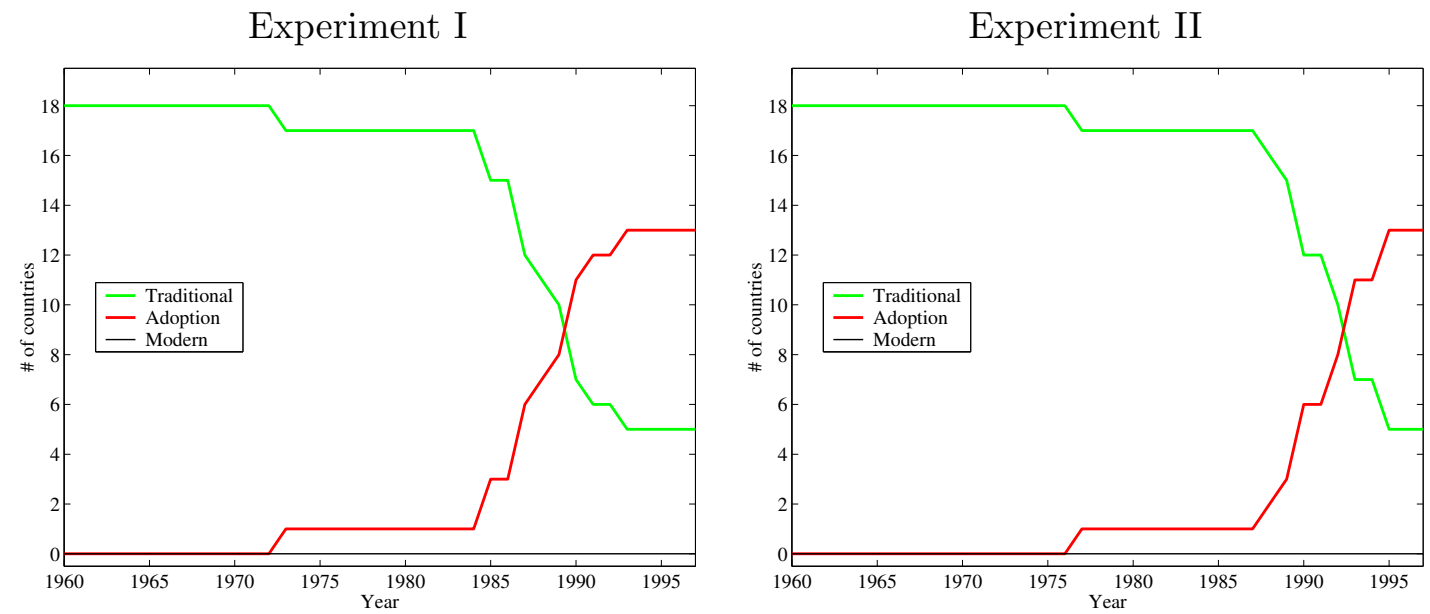

sooner in experiment I, as the first country enters the adoption phase in 1972, whereas under experiment II, the first country to adopt the modern technology waited until 1976. In both cases, most economies enter the adoption phase in the 80s and no country has totally abandoned the traditional technology by the end of the sample.

\section{Conclusion}

Over the last quarter of a century, economic performance across major industrialized countries has been characterized by some country having good performance in terms of labor productivity growth while other having had good performance in terms of employment growth. Very few countries have had good performance on both fronts over long periods. ${ }^{31}$ The object of this paper has been to shed light regarding the apparent increasing tradeoff between productivity and employment growth observed since the mid-seventies. Our answer is that this tradeoff has emerged as the result of these countries undergoing a major technological change. In particular, we have shown how the endogenous adoption of a new production process can induce an AK accumulation phase where the negative tradeoff between employment growth and productivity growth becomes greatly amplified for a temporary period. Our estimates of

\footnotetext{
${ }^{31}$ Among the very advanced countries, only Luxembourg has performed remarkably well on both front. Ireland is another possible exception, but in the early part of our sample, it was so far behind the set of advance industrialized countries that it appears to us to deserve an more idiosyncratic explanation. For example, the reduction of corporate taxation in Ireland (which in our model can have huge effects) may key to understanding the dramatic catchup experienced in Ireland.
} 
this process suggests that it has been in effect for the last 20 to 25 years, and that only now may it becoming to an end. Obviously, if it is coming to an end, it suggests that countries with high rates of population growth may perform relatively better in terms of labor productivity growth in the near future than in the recent past. The US experience since 1996 provides some preliminary evidence to this effect whereby, as documented by Jorgensen and Stiroh (2000), labor productivity growth has recently picked up due to an increase in the speed of capital deepening. 


\section{References}

[1]. Acemoglu, Daron, Changes in Unemployment and Wage Inequality: An Alternative Theory and Some Evidence, American Economic Review, December 1999, 1259-1278.

[2]. Barro, Robert J., and Xavier Sala-i-Martin, Economic Growth, Cambridge, MA: MIT Press 1995.

[3]. Basu, Susanto and David Weil Appropriate Technology and Growth, Quarterly Journal of Economics, 113(4), November 1998: 1025-54.

[4]. Beaudry, Paul and David Green, What is Driving US and Canadian Wages: Endogenous Technical Change or Endogenous Choice of Technique?, N.B.E.R. working Paper 6853, December 1998.

[5]. Beaudry, Paul and David Green, The Changing Structure of Wages in the US and Germany: What Explains the Difference?, N.B.E.R. working Paper 7697, May 2000.

[6]. Berman, Eli, John Bound and Stephen Machin, Implications of Skilled-biased Technological Change: International Evidence, Quarterly Journal of Economics, November 1998, 1245-1280.

[7]. Olivier Blanchard, The Medium Run, Brookings Paper on Economic Activity, 1997.

[8]. Bresnahan, Timothy and Manuel Trajtenberg General Purpose Technologies: Engines of Growth?, Journal of Econometrics, 65 (1995), pp. 83-108.

[9]. Caselli, Francesco, Technological Revolutions, American Economic Review, March 1999, 78-102.

[10]. Dale W. Jorgensen and Eric Yip Whatever Happened to Productivity Growth, mimeo Harvard University, June 1999.

[11]. Dale W. Jorgensen and Kevin J. Stiroh, Raising the speed limit: US Economic Growth in the Information Age, OECD ECO/WKP 2000-34, 2000.

[12]. Mankiw, N. Gregory, David Romer and David Weil, A Contribution to the Empirics of Economic Growth, Quarterly Journal of Economics, 107 (May), 1992, 407-437.

[13]. Obstfeld, Maurice and Kenneth Rogoff, The Six Major Puzzles in International Macroeconomics: Is There a Common Cause?, NBER Macroeconomics Annual 2000, Ben Bernanke and Kenneth Rogoff (eds). 
[14]. Solow, Robert, A Contribution to the Theory of Economic Growth, Quaterly Journal of Economics, 70, 1956, 65-94.

[15]. Ventura, Jaume, Growth and Interdependence, Quarterly Journal of Economics, 112, (1997), pp. 57-84.

[16]. Zeira, Joseph, Workers, Machines and Economic Growth, Quarterly Journal of Economics, 113(4), 1998, 1091-1118. 


\section{A Proof of propositions}

\section{A.1 Proof of Proposition 1}

During the adoption phase, both $K_{i, t}^{T}, K_{i, t}^{M}, L_{i, t}^{T}, L_{i, t}^{M}$ are in use and satisfy

$$
\begin{array}{r}
K_{i, t}=K_{i, t}^{T}+K_{i, t}^{M} \\
L_{i, t}=L_{i, t}^{T}+L_{i, t}^{M}
\end{array}
$$

During this phase, the first order conditions associated to the firm problem imply

$$
\frac{K_{i, t}^{M}}{\theta_{t} L_{i, t}^{M}}=\Phi_{t}^{\frac{1}{\alpha-\beta}}\left(\frac{\alpha}{\beta}\right)^{\frac{\alpha}{\beta-\alpha}}\left(\frac{1-\alpha}{1-\beta}\right)^{\frac{1-\alpha}{\beta-\alpha}} \equiv \Gamma_{t}^{M}
$$

and

$$
\frac{K_{i, t}^{T}}{\theta_{t} L_{i, t}^{T}}=\Phi_{t}^{\frac{1}{\alpha-\beta}}\left(\frac{\alpha}{\beta}\right)^{\frac{\beta}{\beta-\alpha}}\left(\frac{1-\alpha}{1-\beta}\right)^{\frac{1-\beta}{\beta-\alpha}} \equiv \Gamma_{t}^{T}=\frac{\alpha(1-\beta)}{\beta(1-\alpha)} \Gamma_{t}^{M}
$$

Using the above equations to solve for $K_{i, t}^{T}$ and $K_{i, t}^{M}$ yields

$$
\begin{aligned}
K_{i, t}^{T} & =\frac{\alpha(1-\beta)}{\beta-\alpha} \Gamma_{t}^{M} \theta_{t} L_{i, t}-\frac{\alpha(1-\beta)}{\beta-\alpha} K_{i, t} \\
K_{i, t}^{M} & =\frac{\beta(1-\alpha)}{\beta-\alpha} K_{i, t}-\frac{\alpha(1-\beta)}{\beta-\alpha} \Gamma_{t}^{M} \theta_{t} L_{i, t}
\end{aligned}
$$

then we have

(i) When only the traditional technology is at work, we have $K_{i, t}=K_{i, t}^{T}$ and $L_{i, t}=L_{i, t}^{T}$.

For such a situation to be optimal, the first order conditions imply

$$
\frac{K_{i, t}}{\theta_{t} L_{i, t}} \leqslant \Gamma_{t}^{T}=\frac{\alpha(1-\beta)}{\beta(1-\alpha)} \Gamma_{t}^{M}
$$

or, using the definition of $\Gamma_{t}^{T}$

$$
\frac{K_{i, t}}{\theta_{t} L_{i, t}} \leqslant \Phi_{t}^{\frac{1}{\alpha-\beta}}\left(\frac{\alpha}{\beta}\right)^{\frac{\beta}{\beta-\alpha}}\left(\frac{1-\alpha}{1-\beta}\right)^{\frac{1-\beta}{\beta-\alpha}}
$$

(ii) When only the modern technology is at work, we have $K_{i, t}=K_{i, t}^{M}$ and $L_{i, t}=L_{i, t}^{M}$. For such a situation to be optimal, the first order conditions imply

$$
\frac{K_{i, t}}{\theta_{t} L_{i, t}} \geqslant \Gamma_{t}^{M}
$$


or, using the definition of $\Gamma_{t}^{M}$

$$
\frac{K_{i, t}}{\theta_{t} L_{i, t}} \geqslant \Phi_{t}^{\frac{1}{\alpha-\beta}}\left(\frac{\alpha}{\beta}\right)^{\frac{\alpha}{\beta-\alpha}}\left(\frac{1-\alpha}{1-\beta}\right)^{\frac{1-\alpha}{\beta-\alpha}}
$$

The result then follows.

\section{A.2 Proof of proposition 2}

Recall from the proof of Proposition 1, that during the adoption phase, we have

$$
\begin{aligned}
K_{i, t}^{T} & =\frac{\alpha(1-\beta)}{\beta-\alpha} \Gamma_{t}^{M} \theta_{t} L_{i, t}-\frac{\alpha(1-\beta)}{\beta-\alpha} K_{i, t} \\
K_{i, t}^{M} & =\frac{\beta(1-\alpha)}{\beta-\alpha} K_{i, t}-\frac{\alpha(1-\beta)}{\beta-\alpha} \Gamma_{t}^{M} \theta_{t} L_{i, t}
\end{aligned}
$$

and

$$
\begin{aligned}
Y_{i, t}^{T} & =\Gamma_{t}^{T^{\alpha-1}} K_{i, t}^{T} \\
Y_{i, t}^{M} & =\Phi_{t} \Gamma_{t}^{M^{\beta-1}} K_{i, t}^{M}
\end{aligned}
$$

From these equations we can derive that

$$
\Phi_{t} \Gamma_{t}^{M \beta-1}=\frac{\alpha}{\beta} \Gamma_{t}^{T^{\alpha-1}}
$$

and hence output can be written as

$$
Y_{i, t}=Y_{i, t}^{T}+Y_{i, t}^{M}=\Gamma_{t}^{T^{\alpha-1}}\left(K_{i, t}^{T}+\frac{\alpha}{\beta} K_{i, t}^{M}\right)
$$

Using the solution for $K_{i, t}^{T}$ and $K_{i, t}^{M}$, we obtain

$$
Y_{i, t}=\alpha \Gamma_{t}^{T^{\alpha-1}} K_{i, t}+(1-\alpha) \Gamma_{t}^{M^{\alpha}} \theta_{t} L_{i, t}
$$

which is of the form $A K+B \theta_{t} L$.

\section{A.3 Proof of proposition 3}

Let us define the growth in output-per-worker at time $t$ as the log-difference between periods $t$ and $t-1$ (which is consistent with our empirical analysis). In the absence of the alternative technology, this difference is given by

$$
\ln \frac{Y_{i, t}}{L_{i, t}}-\ln \frac{Y_{i, t-1}}{L_{i, t-1}}=\alpha \ln \frac{K_{i, t}}{L_{i, t}}-\alpha \ln \frac{K_{i, t-1}}{L_{i, t-1}}+(1-\alpha)(1+\gamma)
$$


Using $\gamma_{i, t}^{k}$ to represent $\frac{K_{i, t}-K_{i, t-1}}{K_{i, t-1}}$, the growth of output-per-worker can be rewritten as

$$
\ln \frac{Y_{i, t}}{L_{i, t}}-\ln \frac{Y_{i, t-1}}{L_{i, t-1}}=\alpha \ln \left(\frac{\left(1+\gamma_{i, t}^{k}\right)}{\left(1+\eta_{i}\right)}\right)+(1-\alpha)(1+\gamma)
$$

from which, we get

$$
\frac{\partial\left(\ln \frac{Y_{i, t}}{L_{i, t}}-\ln \frac{Y_{i, t-1}}{L_{i, t-1}}\right)}{\partial \ln \frac{Y_{i, t-1}}{L_{i, t-1}}}=\frac{\alpha}{1+\gamma_{i, t}^{k}} \times \frac{\partial \gamma_{i, t}^{k}}{\partial \frac{Y_{i, t-1}}{L_{i, t-1}}}
$$

and

$$
\frac{\partial\left(\ln \frac{Y_{i, t}}{L_{i, t}}-\ln \frac{Y_{i, t-1}}{L_{i, t-1}}\right)}{\partial \ln \left(1+\eta_{i}\right)}=\alpha\left(\frac{1}{1+\gamma_{i, t}^{k}} \times \frac{\partial \gamma_{i, t}^{k}}{\partial \ln \left(1+\eta_{i}\right)}-1\right)
$$

Recall that $\gamma_{i, t}^{k}$ is implicitly determined by the condition

$$
r_{t}+\delta+\nu\left(\gamma_{i, t}^{k}\right)=\alpha\left(\left(\frac{Y_{i, t-1}}{L_{i, t-1}}\right)^{\frac{1}{\alpha}} \frac{\left(1+\gamma_{i, t}^{k}\right)}{\theta_{t}\left(1+\eta_{i}\right)}\right)^{\alpha-1}
$$

from which we get

$$
\frac{\partial \gamma_{i, t}^{k}}{\partial \frac{Y_{i, t-1}}{L_{i, t-1}}}=\frac{(\alpha-1)\left(\frac{Y_{i, t-1}}{L_{i, t-1}}\right)^{-\frac{1}{\alpha}}\left(1+\gamma_{i, t}^{k}\right)^{\alpha-1}\left(\theta_{t}\left(1+\eta_{i}\right)\right)^{1-\alpha}}{\nu^{\prime}\left(\gamma_{i, t}^{k}\right)+\alpha(1-\alpha)\left(\frac{Y_{i, t-1}}{L_{i, t-1}}\right)^{\frac{\alpha-1}{\alpha}}\left(1+\gamma_{i, t}^{k}\right)^{\alpha-2}\left(\theta_{t}\left(1+\eta_{i}\right)\right)^{1-\alpha}}<0
$$

and

$$
\frac{\partial \gamma_{i, t}^{k}}{\partial \ln \left(1+\eta_{i}\right)}=\frac{\alpha(1-\alpha)\left(\frac{Y_{i, t-1}}{L_{i, t-1}}\right)^{\frac{\alpha-1}{\alpha}}\left(1+\gamma_{i, t}^{k}\right)^{\alpha-1}\left(\theta_{t}\left(1+\eta_{i}\right)\right)^{1-\alpha}}{\nu^{\prime}\left(\gamma_{i, t}^{k}\right)+\alpha(1-\alpha)\left(\frac{Y_{i, t-1}}{L_{i, t-1}}\right)^{\frac{\alpha-1}{\alpha}}\left(1+\gamma_{i, t}^{k}\right)^{\alpha-2}\left(\theta_{t}\left(1+\eta_{i}\right)\right)^{1-\alpha}}>0
$$

It then directly follows that

$$
\frac{\partial\left(\ln \frac{Y_{i, t}}{L_{i, t}}-\ln \frac{Y_{i, t-1}}{L_{i, t-1}}\right)}{\partial \frac{Y_{i, t-1}}{L_{i, t-1}}}<0
$$

Further, it is straightforward to check that the term inside the parenthesis in (A.14) is negative, which together with $\frac{\partial \gamma_{i, t}^{k}}{\partial \ln \left(1+\eta_{i}\right)}>0$ implies

$$
-\alpha<\frac{\partial\left(\ln \frac{Y_{i, t}}{L_{i, t}}-\ln \frac{Y_{i, t-1}}{L_{i, t-1}}\right)}{\partial \ln \left(1+\eta_{i}\right)}<0
$$




\section{A.4 Proof of proposition 4}

During the technological adoption phase, the growth rate of output-per-worker can be written as

$$
\begin{aligned}
\ln \frac{Y_{i, t}}{L_{i, t}}-\ln \frac{Y_{i, t-1}}{L_{i, t-1}} & =\ln \left(A \frac{K_{i, t-1}}{L_{i, t-1}} \frac{\left(1+\gamma_{t}^{k}\right)}{\left(1+\eta_{i}\right)}+B \theta_{t}\right)-\ln \left(A \frac{K_{i, t-1}}{L_{i, t-1}}+B \theta_{t-1}\right) \\
& =\ln \left(\left(\frac{Y_{i, t-1}}{L_{i, t-1}}-B \theta_{t-1}\right) \frac{\left(1+\gamma_{t}^{k}\right)}{\left(1+\eta_{i}\right)}+B \theta_{t-1}\right)-\ln \left(\frac{Y_{i, t-1}}{L_{i, t-1}}\right)
\end{aligned}
$$

where the values for $A$ and $B$ are given in the proof of Proposition 2.

In the above equations, note that $\gamma_{t}^{k}$ is not indexed by $i$ since in the transition phase $\gamma_{t}^{k}$ is equal across countries as it is determined by the relationship $\gamma=\nu^{-1}\left(A-r_{t}-\delta\right)$, and is therefore independent from $Y_{i, t-1} / L_{i, t-1}$.

We then have

$$
\frac{\partial\left(\ln \frac{Y_{i, t}}{L_{i, t}}-\ln \frac{Y_{i, t-1}}{L_{i, t-1}}\right)}{\partial \frac{Y_{i, t-1}}{L_{i, t-1}}}=\frac{1}{A \frac{K_{i, t-1}}{L_{i, t-1}} \frac{\left(1+\gamma_{t}^{k}\right)}{\left(1+\eta_{i}\right)}+B \theta_{t}} \frac{\left(1+\gamma_{t}^{k}\right)}{\left(1+\eta_{i}\right)}-\frac{1}{\frac{Y_{i, t}}{L_{i, t}}}
$$

It is then easy to check that

$$
\frac{\partial\left(\ln \frac{Y_{i, t}}{L_{i, t}}-\ln \frac{Y_{i, t-1}}{L_{i, t-1}}\right)}{\partial \frac{Y_{i, t-1}}{L_{i, t-1}}}>0 \Longleftrightarrow \frac{1+\gamma_{t}^{k}}{1+\eta_{i}}>1
$$

that is as long as there is growth in output-per-worker.

Furthermore, we have

$$
\frac{\partial\left(\ln \frac{Y_{i, t}}{L_{i, t}}-\ln \frac{Y_{i, t-1}}{L_{i, t-1}}\right)}{\partial \ln \left(1+\eta_{i}\right)}=-\frac{\left(\frac{Y_{i, t-1}}{L_{i, t-1}}-B \theta_{t-1}\right) \frac{\left(1+\gamma_{t}^{k}\right)}{\left(1+\eta_{i}\right)}}{\left(\frac{Y_{i, t-1}}{L_{i, t-1}}-B \theta_{t-1}\right) \frac{\left(1+\gamma_{t}^{k}\right)}{\left(1+\eta_{i}\right)}+B \theta_{t-1}}
$$

which may be rewritten as

$$
\frac{\partial\left(\ln \frac{Y_{i, t}}{L_{i, t}}-\ln \frac{Y_{i, t-1}}{L_{i, t-1}}\right)}{\partial \ln \left(1+\eta_{i}\right)}=-\frac{Y_{i, t}-B \theta_{t} L_{i, t}}{Y_{i, t}}=-\frac{A K_{i, t}}{Y_{i, t}}=-s_{i}^{k}<-\alpha
$$

where $s_{i}^{k}$ denotes the income share of capital in the technological adoption phase. 